Revista de Derecho

de la Pontificia Universidad Católica de Valparaíso XXXIII (Valparaíso, Chile, $2^{\text {do }}$ Semestre de 2009)

[pp. 391 - 426]

\title{
LA DISCIPLINA CONSTITUCIONAL DEL PRINCIPIO DE SUBSIDIARIEDAD EN ITALIA Y CHILE
}

["The principle of subsidiarity: its constitutional discipline in Italy and Chile"]

\author{
MarTín Loo GutiérReZ*
}

\section{RESUMEN}

El trabajo realiza un sucinto análisis de la evolución histórica del pensamiento jurídico-político sobre el principio de subsidiariedad para luego revisar cómo dicho pensamiento ha influido en la consagración del mencionado principio en la Constitución italiana de 1948 revisada, a estos efectos, el año 2001. A partir de esas conclusiones, el artículo pretende exponer las dudas y conclusiones del autor acerca del alcance de la interpretación que se ha dado a algunas disposiciones de la Constitución chilena de 1980.

Palabras clave: Principio de subsidiaridad - Constitución italiana de 1948 - Reforma a la Constitución italiana de 2001 - Principio de subsidiariedad en la Constitución chilena de 1980.

\begin{abstract}
The article is a brief outline of the historical evolution of the juridical and political thought on the principle of subsidiarity. This evolution is then analysed together with its bearing on the drafting of the Italian Constitution of 1948 and its subsequent amendment, in 2001. Finally, the article seeks to explain the author's misgivings about the usual interpretation of some provisions in the text of the Chilean Constitution of 1980.

KeYwords: Principle of subsidiarity - Italian Constitution 1948 - Ammendment of the Italian Constitution of 2001 - Principle of subsidiarity in the Chilean Constitution of 1980.
\end{abstract}

* Licenciado en Derecho por la Pontificia Universidad Católica de Valparaíso, candidato a Doctor en Derecho público por la II a Università di Roma "Tor Vergata”. El autor agradece los comentarios críticos de los señores R. Bermúdez, L. Cruz y S. Veloso. Contenidas en paréntesis cuadrados (“[ ]") se ofrece la traducción de las citas bibliográficas que se han juzgado más relevantes. 


\section{PREMISA}

El principio de subsidiariedad no deja de despertar interés ni de generar discusiones. Ha sido ensalzado como la fórmula que resuelve los problemas del Estado restituyéndole sus funciones y su ámbito de acción propio y, de la otra parte, ha sido condenado por poner en un lugar preeminente el egoísmo y la avaricia del ser humano como motores de la vida social.

Esta dicotomía se hace presente aun hoy. Nuestra doctrina más reciente ${ }^{1}$ pone en duda que ciertas aplicaciones de este principio hayan sido acogidas por nuestra Carta Fundamental, poniendo en entredicho más de un cuarto de siglo de tranquila convivencia doctrinal sobre la materia.

Estas discusiones se reproducen, con mayor fuerza, en la doctrina italiana, la cual -frente al dato positivo de los artículos 117 inciso $4^{\circ}$, 118 incisos $1^{\circ}$ y $4^{\circ}$, y 120 inciso $2^{\circ}$, de la Constitución ${ }^{2}$, disposiciones que consagran, de modo expreso y para diversas hipótesis, el deber de actuación conforme al principio de subsidiariedad de los sujetos públicos que componen la organización estatal italiana- no deja de discutir sobre el significado de una fórmula lexical explícita, pero carente de un contenido claro o, al menos, unívoco.

Todo esto, creemos, hace interesante detenerse y mirar atrás a la búsqueda de los distintos elementos (de naturaleza bastante heterogénea) que han sido colocados al interior de este contenedor denominado principio de subsidiariedad.

En las siguientes líneas pretendemos realizar una breve exposición acerca de la evolución que ha tenido este principio, desde su origen como postulado filosófico hasta su actual configuración como norma jurídica positiva.

${ }^{1}$ Nos referimos al trabajo de Vallejo Garreton, Rodrigo - Pardow Lorenzo, Diego, Derribando mitos sobre el Estado empresario, en Revista Chilena de Derecho 35 (2008) p. 137, donde los autores afirman que "[...] ni la letra de su texto autoritativo (ser), ni tampoco la función que debe cumplir en una comunidad política sustentada en un principio democrático (deber ser), permiten reconocer un principio de subsidiariedad, a este respecto". Asimismo, pensamos en el trabajo de SCHÜrmanN, Miguel, Orden público económico y principio de subsidiariedad, argumentos para una crítica, en Revista Derecho y Humanidades 12 (2006) pp. 10 ss., donde el autor critica la doctrina que pretende fundar la consagración del principio en el artículo 19 No 21 C.Pol. señalando que "[[...]] en ningún caso se debe aceptar el intento de éstos autores de ver una consagración expresa de un principio, cuando no existe tal".

${ }^{2}$ Estas normas fueron introducidas por la Ley constitucional No 3 de 2001 (publicada en la Gazzetta Ufficiale No 248, del 24 de octubre de 2001) la cual modificó de manera importante el Título $5^{\circ}$ de la carta fundamental italiana (artículos $114 \mathrm{a}$ 133), relativo a las Regiones, Provincias y Municipios. 
El esfuerzo principal estará orientado a la descripción de cómo es entendido el principio en el ordenamiento jurídico italiano, puesto que las diferentes lecturas que se hacen de él -a consecuencia, como se verá, de su reciente consagración positiva en la Constitución republicana de 1948 y de la pertenencia de Italia a la Unión Europea- servirán para demostrar que aquél carece de un único significado y que, por el contrario, debido a la polivalencia que le es propia, puede servir como fundamento de una nueva interpretación de las normas constitucionales del año 1980 que se conforme mejor al rol que, en una democracia, está llamado a cumplir el Estado.

\section{II. ¿QUÉ ES EL PRINCIPIO DE SUBSIDIARIEDAD?}

Los problemas para definir este principio surgen con su ideologización ${ }^{3}$. El qué es este postulado tiene poco o nada que ver con el qué queremos que sea. En otras palabras, la búsqueda de una definición jurídica de este principio ha sido compleja y fruto de una larga evolución, marcada singularmente por el contenido político que se ha otorgado al término.

Será útil comenzar con un ejemplo: lo encontraremos en el diccionario de la Real Academia Española, el cual define este principio como un "criterio que pretende reducir la acción del Estado a lo que la sociedad civil no puede alcanzar por sí misma"4 .

Podríamos afirmar que la Real Academia Española, con su definición, ha logrado capturar, en apenas veinte palabras, la esencia de uno de los conceptos más complejos y polifacéticos de la filosofía política moderna. Sin embargo, como intentaremos demostrar en este trabajo, una definición unívoca acerca del principio de subsidiariedad es difícil de alcanzar. Reconocer su polimorfismo axiológico es, por ello, esencial para una correcta interpretación de su significado.

Como resalta la doctrina más reciente sobre la materia ${ }^{5}$, este principio

\footnotetext{
${ }^{3}$ Por ejemplo, véase: ArEnA, Gregorio, Il principio di sussidiarietà orizzontale nell'artículo 118 u.c. della Costituzione, en Studi in onore di Giorgio Berti (Napoli, Jovene, 2005), I, p. 182, para quien conviene destacar que "[...] il principio di sussidiarietà $[. .$.$] non si presta ad interpretazioni univoche; a seconda dei punti di$ vista e dei valori di riferimento dell'interprete, esso può produrre nella società effetti anche molto diversi fra loro" ("[...] el principio de subsidiariedad [...] no se presta a interpretaciones unívocas; según el punto de vista y de los valores de referencia del intérprete, aquél puede producir en la sociedad efectos muy diversos entre sî")

${ }^{4}$ Diccionario RAE $22^{a}$ edición, en www.rae.es/subsidiariedad

${ }^{5}$ Véase: Millon-Delsol, Chantal, Il principio di sussidiarietà (Trad. it. di Massimo Tringali. Milano, Giuffrè, 2003), p. 1: "L’idea della sussidiarietà risponde alle seguenti domande: perché esiste l'autorità? qual è il suo compito? quale ruolo deve
} 
intenta dilucidar un asunto apremiante durante toda la historia del pensamiento contemporáneo: cómo efectuar una división justa de las tareas de interés general entre la sociedad civil y el poder público.

\section{De Aristóteles al liberalismo clásico (o la subsidiariedad respecto al individuo).}

Ya en la antigüedad griega, Aristóteles se preguntaba acerca del modo de alcanzar la felicidad de los ciudadanos y sobre las tareas que a ese respecto competen a la ciudad (pólis). El individuo, por sí solo puede satisfacer algunas de sus propias carencias, pero es incapaz de ser autárquico, es decir, completamente autosuficiente en la satisfacción de sus necesidades individuales. Por tal motivo, la autarquía (tanto de cada uno de los ciudadanos como del conjunto de ellos) se puede alcanzar con la formación de distintos grupos encargados de ir atendiendo diversas exigencias, aunando sus esfuerzos en la realización de sus propias tareas, las cuales se irán sobreponiendo hasta alcanzar dicho estado de autosuficiencia. La ciudad es, pues, un medio que consentirá al hombre, al ciudadano, de realizar sus fines, pues suplirá las necesidades a las cuales éste no puede dar satisfacción por sí mismo .

Pero, como destaca Millon-Delsol, no se debe confundir la finalidad de la ciudad con la simple o mera suplencia de las incapacidades individuales o de los grupos menores: la sociedad civil es, por el contrario, un ambiente nuevo en el cual el ciudadano y los grupos que él forma (familia, asociaciones profesionales, de artesanos, etc.) se desarrollan hasta alcanzar el máximo de sus potencialidades y, de este modo, perfeccionar su vida ${ }^{7}$.

Las ideas aristotélicas recobrarán relevancia en la doctrina de Santo

avere?" ["La idea de la subsidiariedad responde a las siguientes interrogantes: ¿por qué existe la autoridad?, ¿cuál es su función?, ¿qué rol debe cumplir?”]. Asimismo, Massa PInTo, Ilenia, Il principio di sussidiarietà. Profili storici e costituzionali (Napoli, Jovene, 2003), p. 1: "la formula lessicale principio di sussidiarietà si risol[ve] nella prescrizione di un criterio di preferenza nella relazione tra due o più elementi."

${ }^{6}$ Duret, Paolo, La sussidiarietà orizzontale: le radici e le suggestioni di un concetto, en Jus (2000), p. 98: "[...] la capacità che individui e gruppi ristretti manifestano nelle proprie attività e nei propri compiti specifici non attinge il livello della totale autosuficienza - autercheia - sinonimo di perfezione, che solo la polis, organo propriamente politico può assicurare. Perciò ogni articolazione della società civile (famiglia, villagio, polis) si occupa di rispondere ai bisogni insoddisfatti della sfera inmediatamente inferiore per importanza; tuttavia i compiti dei diversi gruppi non si confondono, ma si sovrappongono e ciascun livello di intervento si muove nel rispetto dell'ambito di capacità proprio degli altri”.

${ }^{7}$ Millon-Delsol, Chantal, Il principio di sussidiarietà, cit. (n. 5), p. 8. 
Tomás de Aquino, esta vez con la sustitución de la entidad ciudadano por la entidad cristiana persona ${ }^{8}$.

La idea tomista sobre la subsidiariedad ${ }^{9}$ se desarrolla en una sociedad organizada en grupos activos que detentan una amplia autonomía (autonomía, es decir, la capacidad de autoregularse y no autarquía). La multiplicidad de grupos y su diversa jerarquía permite explicar la existencia de una autoridad subsidiaria, es decir, que actúa en defecto de ellos, pero no en lugar de ellos.

Como se puede ver, hasta la Edad Media, la idea de la subsidiariedad se relacionaba con las pequeñas autoridades sociales, debido a la inexistencia de lo que entendemos hoy por Estado. La presencia de múltiples pero pequeñas organizaciones autónomas (ciudades, corporaciones, universitates, en suma, cuerpos intermedios $)^{10}$, permite hablar de subsidiariedad respecto de aquellas otras organizaciones, situadas en un nivel de jerarquía superior, que pueden pretender un control sobre aquéllas ${ }^{11}$.

Es con el nacimiento de los Estados nacionales que surge el problema respecto a lo que hoy entendemos por principio de subsidiariedad en un sentido estrictamente jurídico ${ }^{12}$. En efecto, como bien destaca MillonDelsol, la cuestión del rol del Estado se transforma en un tema político

${ }^{8}$ Véase: Millon-Delsol, Chantal, Il principio di sussidiarietà, cit. (n. 5), p. 9.

${ }^{9}$ En Chile, sobre la materia, se puede consultar a Astorga Sepúlveda, Cristóbal, Las raices escolásticas del principio de subsidiariedad, en Revista Derecho y Humanidades 12 (2006).

${ }^{10}$ Millon-Delsol, Chantal, Il principio di sussidiarietà, cit. (n. 5), p. 10.

${ }^{11}$ AnTONInI, Luca, Il principio di sussidiarietà orizzontale: da Welfare State a Welfare Society, en Rivista di Diritto Finanziario e Scienza delle Finanze (2000), p. 104: "Alla luce di Aristotele, Tomasso d'Aquino riprese e sviluppò quell'idea, all'interno di un ambiente culturale come era quello del suo tempo, in cui l'individuo non era pensabile individualisticamente, a prescindere cioè dei legami sociali in cui nasceva e si sviluppava".

${ }^{12}$ Motivo por el cual, siguiendo a CASSESE, Sabino, L'aquila e le mosche. Principio di sussidiarietà e diritti amministrativi nell'area europea, en Il foro Italiano (1995), p. 373, quien expresa que "la filosofia politica ha tirato in ballo anche Aristotele ed Althusius, Tocqueville, Proudhon, Tomasso d'Aquino ed altri, con il risultato, però, di far risalire troppo indietro nel tempo la nozione e di aumentare la confusione", creemos que es inútil buscar las explicaciones filosóficas sobre este principio en tiempos demasiado remotos. No se debe olvidar que la subsidiariedad es un concepto aplicable cada vez que uno se puede sustituir a otro en la realización de una determinada actividad: situaciones de este tipo las encontraremos en todos los ámbitos de la vida (incluso de la vida familiar) y en todos los tiempos. Opinamos, en consecuencia, que el desarrollo contemporáneo de esta idea sea la que nos permitirá entender de mejor modo sus implicaciones políticas y jurídicas. 
central sólo a partir del momento en que el Estado existe como tal y se desarrolla, sea en exceso, sea insuficientemente ${ }^{13}$.

Este es el problema que enfrentan, en la primera mitad del siglo XIX, Hegel y Tocqueville ${ }^{14}$. El primero, en una Alemania donde no existe una autoridad central fuerte y que, por ello, se encuentra disgregada en múltiples autonomías locales carentes de un verdadero poder para hacer frente a sus vecinos; el segundo, en una Francia cuyo poder público es un "enorme aparato que por cientos de kilómetros se encarga de administrar problemas liliputienses"15, es decir, un Estado que controla, reglamenta y organiza hasta el más mínimo detalle la vida de sus ciudadanos.

La reacción de Hegel es aquella que influirá en las ideas liberales de modo más claro. Para el filósofo alemán "el Estado puede contar con la acción de los grupos y, por ende, limitar sus intervenciones al mínimo necesario, es decir, a aquello que los grupos no pueden alcanzar por sí mismos" 16 .

Ésta es la idea que los grupos liberales clásicos recogen y desarrollan: el principio de subsidiariedad como postulado de la no injerencia del Estado en los asuntos de la sociedad, puesto que, para ellos, el bien común se realizará sólo si los individuos logran alcanzar sus propios intereses personales, es decir, se percibe al bien común como el resultado de la suma de los bienes individuales. Para que ello sea posible, el Estado debe abstenerse de intervenir en los asuntos de los individuos y, por ende, de la sociedad civil. Por lo anterior, el Estado no puede tener más pretensión que garantizar que los particulares alcancen sus propios fines ${ }^{17}$, sin interferir en el logro

${ }^{13}$ Millon-Delsol, Chantal, Il principio di sussidiarietà, cit. (n. 5), p. 13.

${ }^{14}$ De acuerdo con ANTONINI, Luca, Il principio di sussidiarietà orizzontale, cit. (n. 11), p. 105: "[...] la difesa del pluralismo sociale dall'invasità dello Stato [è] stato poi ribadito da notevoli autori, primo fra tutti Tocqueville".

${ }^{15}$ Millon-Delsol, Chantal, Il principio di sussidiarietà, cit. (n. 5), p. 14.

${ }^{16}$ Ibíd., p. 15.

${ }^{17}$ Ibíd., p. 16: "Lo Stato non può avere altra pretesa se non quella di garantire i fini particolari. Non è depositario di un compito che riguarda tutta la società perché essa ha solo un'esistenza astratta, e non può voler nulla per se stessa come tutto". También, Albanese, Alessandra, Il principio di sussidiarietà orizzontale: autonomia sociale e compiti pubblici, en Diritto Pubblico (2002), p. 59: "La formulazione più radicale del principio di sussidiarietà nel pensiero liberale si fonda soprattutto sull'affermazione della riduzione dell'intervento statale al minimo necessario per garantire la libertà e la convivenza degli individui”. ["La formulación más radical del principio de subsidiariedad en el pensamiento liberal se funda sobre todo, en la afirmación de la reducción de la intervención estatal al mínimo necesario para garantizar la libertad y la convivencia de los individuos".] 
de ese objetivo individual de alcanzar el propio bien que, a la larga, portará al logro del bien común.

Otro punto relevante -mejor dicho, clave- para comprender las ideas de los liberales clásicos sobre esta materia, es la desconfianza y rechazo que expresan hacia los cuerpos intermedios. Esta actitud negativa respecto de estos grupos significará que, en la concepción liberal, exista una directa relación entre individuo y el Estado. Éste, que en la práctica es omnipotente, sólo cuenta con dos alternativas: u otorga libertad a sus ciudadanos o bien les cuida como si fueren niños, negándoles, como consecuencia, el desarrollo de sus potencialidades. La desproporción que existe entre ellos es demasiada como para consentir cualquier tipo de colaboración ${ }^{18}$, en un plano de (al menos teórica) igualdad ${ }^{19}$.

Como podemos ver, la concepción liberal de la subsidiariedad es fundamentalmente bipolar: pone en confrontación directa al individuo y al Estado; opone la libertad individual y la intervención pública, se funda en una concepción antagonista de la relación entre el Estado, por una parte, y el individuo, por otra. En este cuadro, la función del principio de subsidiariedad es la delimitación (o, mejor dicho, la limitación) de la intervención pública en los asuntos individuales y sociales ${ }^{20}$.

Luego del exceso que representa entender al Estado como un enemigo de la libertad individual y, por ende, como un mal cuyas intervenciones deben ser reducidas al mínimo, surgieron las ideas que llevan a la configuración contemporánea de este principio.

${ }^{18}$ Millon-Delsol, Chantal, Il principio di sussidiarietà, cit. (n. 5), p. 16, "Il liberalismo vede con sospetto, nello sviluppo dei gruppi, la nascita di particolari dispotismi. Perciò ha combautto le corporazioni”. Asimismo, Massa PINTO, Ilenia, Il principio di sussidiarietà. Profili storici e costituzionali, cit. (n. 5), p. 4: "Tale proclamazione si espiega [...] con il tentativo operato dalla Chiesa di opporsi alla condanna liberali dei c.d. "corpi intermedi" tra l'individio e lo Stato" "Tal proclamación se explica [...] en el intento de la Iglesia de oponerse a la condena hecha por el pensamiento de los, así llamados, "cuerpos intermedios" entre el individuo y el Estado").

${ }^{19}$ La colaboración entre Estado y particulares es esencial para comprender la evolución que, al interior de los Estados sociales europeos, ha tenido el pensamiento sobre el principio de subsidiariedad. Esta colaboración es la que permite justificar la actuación de los particulares en aquellas tareas que el Estado ha asumido progresivamente como propias en el marco de sus funciones como proveedor de servicios sociales y de satisfacción de necesidades comunes al interior de la sociedad. Es a partir de este concepto, la colaboración del particular con el Estado, que han surgido figuras que inciden en la concepción de la relación jurídica Administración-ciudadano y, en particular, la novel teorización sobre el "contrato de colaboración públicoprivada”.

${ }^{20}$ Albanese, Alessandra, Il principio di sussidiarietà orizzontale: autonomia sociale e compiti pubblici, cit. (n. 17), p. 60. 
2. La doctrina social de la Iglesia o la subsidiariedad respecto de los cuerpos intermedios.

Las ideas que sostiene esta relevante doctrina de la Iglesia Católica surgen del pensamiento de dos religiosos: el primero, alemán, Wilhelm Emmanuel Freiherr von Ketteler; el segundo, italiano, Luigi Taparelli D’Azeglio ${ }^{21}$.

Aquél reflexiona en el contexto que le ofrece la burocracia prusiana de su tiempo, es decir, un Estado omnipresente e intervencionista en los asuntos de la vida social. Buscaba encontrar el equilibrio en la injerencia estatal en las cuestiones sociales que aquejaban la Alemania de la primera mitad del siglo XIX pero, cuidando que estas intervenciones no fueran más allá de lo necesario. El segundo, en cambio, buscó rehabilitar el valor de los cuerpos intermedios, precisando las modalidades de intervención del Estado en una sociedad que se estructura sobre la base de su existencia. Esta idea (el reconocimiento de la existencia y el respeto hacia los cuerpos intermedios) será clave para entender el desarrollo que el principio de subsidiariedad alcanzará con la doctrina social de la Iglesia, una vez que ella es formulada explícitamente en los diversos documentos eclesiásticos que la han hecho su centro de atención e inspiración.

La preocupación social de la Iglesia se comienza a sentir hacia fines del siglo XIX, solicitada por las circunstancias históricas que exigían una intervención en tal sentido. Motivado por estos particulares factores, el Papa León XIII emana la encíclica Rerum novarum con la cual incita a los Estados a afrontar las graves situaciones sociales que el liberalismo económico estaba generando. "De frente a la dramática crisis que la Iglesia católica debió enfrentar en la segunda mitad del siglo XIX -de la cual, la secularización de la vida civil, el individualismo, el racionalismo y la abstracción universalizante constituyen los aspectos teóricos esenciales-el Magisterio advirtió la necesidad de formular un simbólico neologismo que consintiera continuar a sostener la superioridad axiológica, y por lo tanto, normativa de las sociedades naturales, y en cuya cima no podía sino colocarse la propia Iglesia, respecto a las organizaciones artificiales y al Estado moderno en primer lugar"22.

Es en este cuadro que llega el siglo XX y, con él, la evolución de este

${ }^{21}$ Millon-Delsol, Chantal, Il principio di sussidiarietà, cit. (n. 5), p. 20. En tanto, sobre el sacerdote Luigi Taparelli D’Azeglio véase: el capítulo $4^{\circ}$ de MAsSA PINTO, Ilenia, Il principio di sussidiarietà. Profili storici e costituzionali, cit. (n. 5), pp. 213-305, donde se expone y analiza el pensamiento, el contexto histórico y la influencia que el sacerdote piamontés tuvo en el desarrollo de la doctrina social de la Iglesia católica.

${ }^{22}$ Millon-Delsol, Chantal, Il principio di sussidiarietà, cit. (n. 5), p. 7. 
principio se hace intensa y consciente ${ }^{23}$ : hace su ingreso en normas jurídicas que lo traen a colación y suponen (o mejor dicho, presuponen) su significado.

La paternidad de este principio ha sido pacíficamente atribuida al Papa Pío XI ${ }^{24}$ quien acuña la formula lexical y el concepto contemporáneo en su encíclica Quadragesimo anno de 15 de mayo de $1931^{25}$.

Al origen de la concepción católica de la subsidiariedad se encuentra la necesidad política de subrayar la prevalencia y precedencia ética, ontológica y teleológica ${ }^{26}$ de la persona, del individuo humano por sobre la organización política del Estado. Esta doctrina predica la misma prevalencia y precedencia respecto de las organizaciones que surgen al interior de la sociedad civil (los cuerpos intermedios), entendidas como "organizaciones naturales" por contraposición a aquella organización "no natural" denominada Estado.

Según este pensamiento, el Estado se encuentra llamado a operar en el caso que los individuos, por sí mismos o a través de sus organizaciones sociales no sean capaces de llevar a cabo las tareas necesarias para la satisfacción de sus incumbencias y necesidades ${ }^{27}$. Por ello, la acción del Estado debe

${ }^{23}$ Así, al menos en relación con la segunda mitad del siglo XX, Frosini, Tommaso Edoardo, Sussidiarietà (Principio di) (Dir. cost.), en Enciclopedia Giuridica (Milano, Giuffrè, 2008), Anali II, II, p. 1.133.

${ }^{24}$ Massa PInTo, Ilenia, Il principio di sussidiarietà. Profli storici e costituzionali, cit. (n. 5), p. 10: "La formula lessicale principio di sussidiarietà, riferita al contesto dell'organizzazione sociale, comparve dunque per prima volta nel lessico del Magistero della Chiesa cattolica, nell'enciclica Quadragesimo anno"; ANTONINI, Luca, Il principio di sussidiarietà orizzontale, cit. (n. 11), p. 105: "La prima enunciazione avvenne nella Enciclica Quadragesimo anno [...]". En Chile, entre otros, SAN FranCISCO Reyes, Alejandro, Jaime Guzmán y el principio de subsidiariedad educacional en la Constitución de 1980, en Revista Chilena de Derecho 19 (1992), p. 529: "El gran personaje en la evolución de este principio es el Papa Pío XI, a quien se le debe la creación de la expresión "Principio de Subsidiariedad" (que proviene del latín subsidium, ayuda de la reserva)".

25 "80. [...] Por lo tanto, tengan muy presente los gobernantes que, mientras más vigorosamente reine, salvado este principio de función "subsidiaria", el orden jerárquico entre las diversas asociaciones, tanto más firme será no sólo la autoridad, sino también la eficiencia social, y tanto más feliz y próspero el estado de la nación”. PAPA Pío XI, Carta encíclica Quadragesimo anno (1931), para. 80, accedido en www. vatican.va.

${ }^{26}$ Covarrubias Cuevas, Ignacio, El principio de subsidiariedad, en Navarro BeLTRÁN, Enrique (ed.), Veinte años de la Constitución chilena: 1981-2001 (Santiago, Editorial Jurídica ConoSur, 2001), p. 78.

${ }^{27}$ PAPa Pío XI, Carta encíclica Quadragesimo anno, cit. (n. 25), para. 79: “[...] como no se puede quitar a los individuos y dar a la comunidad lo que ellos pueden realizar con su propio esfuerzo e industria, así tampoco es justo, constituyendo un 
ser limitada a las medidas necesarias a reactivar la iniciativa y la actividad de los individuos y de sus organizaciones cuando esta sea temporalmente incapaz de hacer frente a la satisfacción de dichos asuntos.

De las ideas expresadas en la encíclica Quadragesimo anno se desprende, en primer término, una pretensión de delimitación (y ya no de mera limitación) del ejercicio del poder del Estado y la correlativa protección de la dignidad del individuo y, sobre todo, de los cuerpos intermedios y su iniciativa. El Estado se encuentra legitimado a actuar en aquellos casos que, por la naturaleza y la dimensión de las tareas, el individuo o las comunidades a él más cercanas no sean capaces de afrontar ${ }^{28}$.

Esta doctrina, sin embargo, no olvida que es también un deber del Estado proveer ayuda a quienes sean incapaces de hacer frente a sus carencias; iniciativa e intervención pública que viene justificada en el deber de solidaridad ${ }^{29}$.

Asimismo, la doctrina social de la Iglesia intenta subrayar que las tareas del Estado que a éste resultan irrenunciables -y, por ello, más allá del ámbito de aplicación del principio-son aquellas legadas al ejercicio de los poderes públicos los cuales deben actuar "dirigiendo, vigilando, urgiendo y castigando, según el caso requiera y la necesidad exija” ${ }^{30}$.

grave perjuicio y perturbación del recto orden, quitar a las comunidades menores e inferiores lo que ellas pueden hacer y proporcionar y dárselo a una sociedad mayor y más elevada, ya que toda acción de la sociedad, por su propia fuerza y naturaleza, debe prestar ayuda a los miembros del cuerpo social, pero no destruirlos y absorberlos"; AnTONINI, Luca, Il principio di sussidiarietà orizzontale, cit. (n. 11), p. 106: "Da qui il ruolo sussidiario dello Stato, legittimato ad intervenire solo in quei casi in cui, per la natura e la dimensione dei problemi, il singolo o la comunità a lui più immediatamente vicina, non sono in grado di autoregolarsi e gestirsi da soli" ("De aquí el rol subsidiario del Estado, legitimado a intervenir solamente en aquellos casos en los cuales, por la naturaleza y la dimensión de los problemas, el individuo o las comunidades que le están más cercanas, no son capaces de autoregularse y gestionarse separadamente").

${ }^{28}$ Papa Pío XI, Carta encíclica Quadragesimo anno, cit. (n. 25), para. 80: "Conviene, por tanto, que la suprema autoridad del Estado permita resolver a las asociaciones inferiores aquellos asuntos y cuidados de menor importancia, en los cuales, por lo demás perdería mucho tiempo, con lo cual logrará realizar más libre, más firme y más eficazmente todo aquello que es de su exclusiva competencia, en cuanto que sólo él puede realizar, dirigiendo, vigilando, urgiendo y castigando, según el caso requiera y la necesidad exija".

${ }^{29}$ Sobre la relación entre subsidiariedad y solidaridad, véase: COVArRubias CUEVAS, Ignacio, El principio de subsidiariedad, cit. (n. 26), pp. 89 ss.

${ }^{30}$ Papa Pío XI, Carta encíclica Quadragesimo anno, cit. (n. 25), par. 20. En Chile, de igual opinión, Ruiz-Tagle Vial, Pablo, Principios constitucionales del Estado empresario, en Revista de Derecho Público 62 (2000), p. 54: "La encíclica también 
Como indica la doctrina ${ }^{31}$, en el pensamiento manifestado por la encíclica Quadragesimo anno resalta no tanto el aspecto negativo del principio (aquél que prescribe la abstención del Estado) sino, por el contrario, su aspecto positivo, es decir, la promoción de la intervención pública ahí donde exista la necesidad de sostén y estímulo de la actividad e iniciativa de los particulares y de las organizaciones por ellos constituidas, las cuales se encuentran en una posición intermedia entre el Estado y el individuo.

Por otro lado, se puede afirmar que esta encíclica es, como lo fue la Rerum novarum, una reacción a las circunstancias históricas que reinaban al momento de su emanación.

En efecto, esta forma de concebir el rol del Estado y de la sociedad civil intenta ser una respuesta a las ideas expresadas por el fascismo italiano que iban ganando terreno en la segunda mitad de la década de los años Veinte del siglo pasado ${ }^{32}$. No debe olvidarse que esta ideología política predicaba una especie de subsidiariedad que se había manifestado, por ejemplo, en el artículo IX de la "Carta del Trabajo" del Gran Consejo del Fascismo de 21 de abril de $1927^{33}$.

concibe la "autoridad politica suprema" como titular de una "competencia exclusiva"; y expresa que estas tareas de competencia exclusiva comprenden "dirigir, vigilar, estimular, reprimir, según los casos y necesidad lo exigen” (cursivas en el original). Esta idea se ha revertido en nuestra jurisprudencia constitucional, la cual estima que el principio de subsidiariedad no puede comportar que el Estado transfiera el despliegue de actividades que conlleven el ejercicio del imperium público a favor de los particulares, siendo inconstitucional -por este motivo- la ley que así lo autorice. Véase: voto disidente (especialmente el considerando octavo) de la sentencia de 1 de julio de 2008 dictada en causa rol No 1024-2008, con motivo del control de constitucionalidad del proyecto de ley sobre recuperación del bosque nativo y fomento forestal.

${ }^{31}$ Albanese, Alessandra, Il principio di sussidiarietà orizzontale: autonomia sociale e compiti pubblici, cit. (n. 17), p. 64: "l'Enciclica afferma con chiarezza l'importanza del valore positivo dell'intervento sussidiario dello Stato, accanto alla affermazione, altretanto netta, della necessità di delimitarne i confini affinché le forze sociali non siano 'distrutte o assorbite" ("la encíclica afirma con claridad la importancia del valor positivo de la intervención subsidiaria del Estado, al lado de la afirmación, del mismo modo clara, de la necesidad de delimitar los confines con el objeto de que las fuerzas sociales no sean 'destruidas o absorbidas'”).

${ }^{32}$ Frosini, Tommaso Edoardo, Sussidiarietà (Principio di) (Dir. cost.), cit. (n. 23), p. 1.135: "C'è da dire che tali affermazioni (de la encíclica Quadragesimo anno, $n$. del a.) furono proclamate in aperta polemica antiliberale, oltreché in opposizione al regime fascista. Da un lato, cioè contro la condanna liberale dei cosiddetti "corpi intermedi"; dall'altro, contro l'esaltazione dello Stato fatta dal regime" fascista de Mussolini”.

33 "IX. L'intervento dello Stato nella produzione economica ha luogo soltanto quando manchi o sia insufficiente l'iniziativa privata o quando siano in giuoco interessi politici dello Stato. Tale intervento può assumere la forma del controllo, dell'incoraggiamento e 
Resulta posible afirmar, en consecuencia, que la idea política acerca de este principio haya sido influenciada por la interpretación que de ella hizo el fascismo italiano. Pero, al mismo tiempo, es necesario resaltar que es un error sostener que el principio de subsidiariedad, en la forma que hoy conoce, sea de concepción fascista como, en efecto, lo demuestran las investigaciones de Massa Pinto. Esta autora impugna esta pretendida paternidad señalando que la concepción social de la ideología fascista propugnaba una masiva intervención del Estado en las cuestiones de la vida de la comunidad, a través de diversas actuaciones orientadas al control de la instrucción pública, a la gestión económica directa de las industrias, etc. ${ }^{34}$

Por lo anterior, creemos que la diferencia fundamental entre la "subsidiariedad" fascista y la subsidiariedad concebida a partir de la doctrina social de la Iglesia Católica se encuentra en el tratamiento que una y otra reservan a la noción y figura de los "grupos intermedios".

Para el fascismo italiano, entre el Estado y el individuo no existen asociaciones ni corporaciones que operen en ámbitos propios y exclusivos; el individuo se encuentra sometido directamente al poder del Estado y en relación directa con él, sin intermediarios de ninguna clase. En la concepción fascista, el Estado es un valor y, por ende, se le debe confiar la misión de reconfigurar la sociedad, de transformarla a través de la masiva intervención pública en todos los ámbitos de la vida social.

En cambio, la doctrina social de la Iglesia Católica, por el contrario, defiende la existencia de las sociedades naturales que surgen entre los individuos (los tantas veces mencionados cuerpos intermedios) a través de los cuales la sociedad -también ella, una agrupación natural y anterior al Estado- se organiza y busca satisfacer sus necesidades.

En definitiva, la Iglesia Católica busca salvaguardar estas asociaciones de la acción absorbente y destructiva del Estado, al cual no se debe confiar el desarrollo de aquellas actividades que bien pueden ser llevadas a cabo por los grupos surgidos espontáneamente al interior del cuerpo social, pero sin olvidar que el Estado puede -y debe- actuar cuando se demuestra la insuficiencia o incapacidad de esos cuerpos intermedios.

della gestione diretta" ("IX. La intervención del Estado en la producción económica tendrá lugar solamente cuando falte o sea insuficiente la iniciativa privada o cuando se encuentren en juego intereses políticos del Estado. Tal intervención puede asumir la forma del control, del incentivo y de la gestión directa").

${ }^{34}$ Massa Pinto, Ilenia, Il principio di sussidiarietà. Profili storici e costituzionali, cit. (n. 5), p. 179: "il totalitarismo fascista, presupponendo invece una concezione pessimistica della società, si pone l'obiettivo di innovarla con un massicio intervento statale" [destacado nuestro]. 


\section{La subsidiariedad en la economía: el neo-liberalismo de Chicago y el ordo-liberalismo de Friburgo.}

Como dijimos, la doctrina social de la Iglesia surge como reacción a los excesos del liberalismo en cuanto defensor del aspecto negativo y abstencionista del principio ${ }^{35}$, es decir, del deber de no injerencia del Estado en la vida social, de la inhibición en el actuar por parte de los poderes públicos.

El liberalismo pone el acento en el conflicto existente entre individuo y Estado, y su manifestación más cruda se encuentra en la expresión "laisez faire", que incitaba al poder público a sustraerse de toda actuación e intervención en la vida social.

El fundamento de esta corriente se encuentra en la salvaguardia de la libertad del individuo. El valor que debe ser protegido de la intervención del Estado no es otro que la libertad individual ${ }^{36}$; según este pensamiento, el Estado sólo es capaz de poner en acto medidas que se oponen a la abierta manifestación y desarrollo de las capacidades de los individuos, en definitiva, que se oponen a la libertad del privado.

Como vemos, esta doctrina pone en duda los fundamentos mismos de la existencia del Estado; éste es un disvalor que puede ser tolerado dentro de límites bien circunscritos, ya que resulta necesario como árbitro de los conflictos individuales que la vida de sociedad hará surgir irremediablemente $e^{37}$ y como encargado de proveer a la satisfacción de aquellas necesidades que los particulares no son capaces de enfrentar como, por ejemplo, la defensa del grupo social.

Una de las manifestaciones más influyentes de esta filosofía se encuentra en aquella línea de pensamiento que ve a la libertad económica como

${ }^{35}$ Albanese, Alessandra, Il principio di sussidiarietà orizzontale, cit. (n. 17), p. 62: "[...] pur nella diversificazione delle manifestazioni del pensiero liberale, resti tuttavia preminente quale aspetto che le accomuna, la enfatizzazione della valenza negativa, cioè di non intervento del potere pubblico [...]".

${ }^{36}$ GÖTZ, Volkmar; HeCKER, Michael, Il principio di sussidiarietà nel diritto costituzionale tedesco con particolare riferimento alla sua dimensione federale, en RINELLA Angelo - Coen Leopoldo, Scarciglia Roberto - Mistò Michele (editores), Sussidiarietà e ordinamenti costituzionali. Esperienze a confronto (Padova, Cedam, 1999), p. 52: "La concezione liberale della sussidiarietà pone l'accento soprattutto sulla sfera della libertà del singolo".

${ }^{37}$ Albanese, Alessandra, Il principio di sussidiarietà orizzontale: autonomia sociale e compiti pubblici, cit. (n. 17), p. 60: "L'intervento dello Stato, secondo il pensiero liberale [...] è legittimo se è 'sussidiario' se è funzionale cioè a garantire la libertà dagli abusi altrui” ("La intervención del Estado, según el pensamiento liberal [...] es legítimo si es 'subsidiario', es decir, si es funcional a garantizar la libertad de los abusos de terceros'). 
una de las manifestaciones más relevantes de la libertad individual. Es, pues, en la política económica, el ámbito donde las ideas propugnadas por los liberales se han desarrollado y expresado de modo más consistente e influyente ${ }^{38}$.

Según esta doctrina, la libertad individual es un valor que debe ser defendido a ultranza. Siendo la libertad de desarrollar actividades económicas una parte fundamental de las libertades del individuo ${ }^{39}$, la doctrina liberal termina destacando la necesidad de limitar al máximo todo tipo de intervención pública en la economía, dado que ellas resultarán perturbadoras del natural curso de los mercados.

Hacia fines del siglo XX, las ideas liberales sobre el mercado son retomadas por los economistas de la Escuela de Chicago, quienes propugnaban un retorno a las concepciones más tradicionales acerca de la libertad en el mercado, pretendiendo un repliegue del Estado de toda función en él, a objeto de entregar a los particulares la mayor cantidad de tareas productivas y de prestación de servicios. Se admite la intervención pública exclusivamente donde las fuerzas del mercado se muestren abiertamente insuficientes.

Este tipo de ideas tuvieron una fuerte influencia en el diseño de los preceptos de contenido económico de nuestra Carta fundamental del 1980,

${ }^{38}$ Duret, Paolo, La sussidiarietà orizzontale, cit. (n. 6), p. 116: "Un altro ambito nel quale la riflessione sulla sussidiarietà come principio giuridico ha avuto modo di manifestarsi riguarda il rapporto tra Stato e mercato e, più in generale, i contenuti e la stessa plausibilità di una 'costituzione economica'"; MosCARINI, Anna, Sussidiarietà e libertà economiche, en Diritto e società (1999), p. 437: "Tra gli innumerevoli usi pragmatici del termine "sussidiarietà", ne esistono almeno tre che interessano da vicino il diritto costituzionale. Il primo significato, talvolta specificato dall'aggettivo "orizzontale" è quello che attiene al rapporto classico tra società e Stato, tra libertà e autorità, tra iniziativa privata e potere impositivo dello Stato: a questo significato appartiene esemplarmente il dibattito sulla sussidiarietà economica, proteso alla ricerca di una terza via alternativa sia al liberalismo classico sia al collettivismo socialista (["Entre los innumerables usos prácticos del término "subsidiariedad", existen al menos tres que inciden en el derecho constitucional. El primer significado, a veces especificado con el adjetivo 'horizontal' es aquel que atiende a la relación clásica entre sociedad y Estado: a este significado pertenece ejemplarmente el debate sobre la subsidiariedad económica encaminado a la búsqueda de una tercera vía alternativa sea al liberalismo clásico, sea al colectivismo socialista").

${ }^{39}$ D'Atena, Antonio, La sussidiarietà tra valori e regole, en Diritto e Giurisprudenza Agraria e dell'Ambiente (2004), p. 70: "Uno dei temi che questa tradizione (la liberal) mette sul tappeto è quello dei rapporti tra Stato e mercato. Alla sua stregua, infatti, configurandosi la libertà d'intrapresa - o con terminologia più tecnica, l'iniziativa economica privata - come un corollario della libertà spettante a tutti gli uomini, lo Stato non dovrebbe comprimere le esplicazioni”. 
como se encuentra documentado por la doctrina nacional ${ }^{40}$.

Finalmente, no se puede pasar por alto que la evolución del principio de subsidiariedad al estado del que actualmente goza, al menos en materia económica, debe mucho a la doctrina alemana desarrollada durante el período posterior a la Segunda Guerra Mundial, la cual aplicó el concepto a la presencia pública en el mercado.

El ordo-liberalismo, nacido al interior de la Universidad de Friburgo en Brisgovia ${ }^{41}$, propugna que el Estado tiene una importante responsabilidad en el mercado: su regulación y su defensa a través de la protección de la libre competencia ${ }^{42}$. Esta escuela inspiró la adopción de medidas económicas que dieron origen al término economía social de mercado ("soziale Markwirtschaft"), sistema económico en el cual el mercado es concebido como la institución presuntivamente más social orientada a la distribución de bienes y que, por ende, debe ser materia de regulación y protección jurídica.

Según esta teoría, al Derecho toca un rol de la mayor relevancia en el sistema económico, cual es, fundar la libertad del mercado y establecer los mecanismos necesarios para su defensa, en el caso que se presenten situaciones que porten a un desequilibrio ${ }^{43}$.

${ }^{40}$ Las ideas de la Escuela de Chicago tuvieron una influencia decisiva en la formulación de la "constitución económica" de la Carta de 1980. Este es uno de los argumentos más importantes en virtud del cual se estima que la Carta de 1980 acoge, implícitamente, el principio de subsidiariedad en materia económica. La bibliografía sobre la materia es amplia, pero en este momento basta recordar a, Carl J., Derecho y economía en la constitución de 1980, en Revista Perspectivas 1 (1998) p. 25, quien señala que: "[...] Chile es un ejemplo de texto no sólo con relación a la economía neoliberal sino también con el enfoque "Chicago" del derecho y de las instituciones". Sobre este argumento, se vea asimismo, la bibliografía indicada en nota 67.

${ }^{41}$ Sobre esta materia: Di Nella, Luca, La Scuola di Friburgo o dell'ordoliberalismo, en IrTI, Natalino (editor), Diritto ed Economia. Problemi e orientamenti teorici (Padova, Cedam, 1999); Gerber, David J., Constitutionalizing the Economy: German Neoliberalism, Competition Law and the "New" Europe, en The American Journal of Comparative Law 42 (1994).

${ }^{42}$ D'Atena, Antonio, Il principio di sussidiarietà, en El mismo, Lezioni di Diritto costituzionale (Torino, Giappichelli, 2001), p. 63: "A ciò è da aggiungere che lo Stato -secondo una prospettiva approfondita dagli ordoliberali di Friburgo- potrebbe (e dovrebbe) intervenire per assolvere un ruolo essenziale: garantire le condizioni di concorrenza" ("Se debe agregar que el Estado -según una perspectiva estudiada por los ordoliberales de Friburgo- podría (y debería) intervenir para cumplir un rol esencial: garantizar las condiciones de la libre competencia").

${ }^{43}$ Di Nella, Luca, La Scuola di Friburgo o dell'ordoliberalismo, cit. (n. 41), p. 179: Se nota que la escuela de Friburgo pretende la libertad del mercado; el neo liberalismo de Chicago, la libertad en el mercado. 
Las concepciones de Friburgo pueden resumirse en dos ideas clave: el mercado será funcional a la sociedad si se le deja libre, pero esta libertad puede llevar a la destrucción del mercado (mediante la formación de monopolios u otras formas de restricción de la libre competencia). Por ende, la labor del Derecho es proteger el libre mercado, estableciendo un ámbito garantizado, protegido y regulado por el ordenamiento jurídico. De esta forma, el mercado se convierte en un instrumento del Derecho en tanto es creado, regulado y protegido por éste ${ }^{44}$.

\section{La subsidiariedad como principio de organización politica: el federa- lismo.}

Si del principio de qua, en sus raíces hasta ahora tratadas, puede decirse que sea un principio de organización social -en cuanto principio que mira a la delimitación de las 'competencias' de la sociedad civil y del Estado- en la perspectiva del federalismo se convierte en un principio de organización político-administrativa ${ }^{45}$.

En esta perspectiva, el principio de subsidiaridad deja de atender a la relación Estado/ciudadano y comienza, en cambio, a observar la relación entre las distintas articulaciones del poder público, mirando a la distribución de las competencias al interior de su estructura política ${ }^{46}$.

Como es sabido, los sistemas federales son métodos de organización política-administrativa que se encuentran orientados a la distribución de las competencias públicas (de legislación, de gobierno y de administración) entre distintos niveles territoriales de entes públicos, asignando funciones a las autoridades que se encuentran en la base de la pirámide organizativa interna del Estado.

En este tipo de organizaciones -al menos en sus formulaciones paradig-

${ }^{44}$ Di Nella, Luca, La Scuola di Friburgo o dell'ordoliberalismo, cit. (n. 41), p. 188

${ }^{45}$ D'Atena, Antonio, Costituzione e principio di sussidiarietà, en Quaderni Costituzionali (2001).

${ }^{46}$ Deaglio, Mario, Sussidiarietà, istituzioni economiche, imprese, en QuAdrIO Curzio, Alberto - ForTis, Marco (ediyores), Valorizzare un'economia forte. L'Italia e il ruolo della sussidiarietà (Bologna, Il Mulino, 2007), p. 321: "Per il pensiero politico $\mathrm{e}$ istituzionale la sussidiarietà rappresenta una regola in base alla quale assegnare il potere e non un principio etico".; GÖTZ, Volkmar; HECKER, Michael, Il principio di sussidiarietà nel diritto costituzionale tedesco con particolare riferimento alla sua dimensione federale, cit. (n. 36), p. 52: "Mentre il principio di sussidiarietà fu fatto valere nell'ottica cristiana e liberale innazi tutto come regola di priorità nel campo delle relazioni fra Stato e società/individuo, nell'ottica delle teorie federali il suo ambito di applicazione si è ampliato alla struttura più interna dello Stato, in considerazione delle delimitazione delle sfere operative di unità statali più grandi e più piccole". 
máticas, como se verá en seguida- se consiente la actuación subsidiaria de la organización pública superior solamente de frente a la incapacidad o inadecuación de la instancia investida originalmente de la competencia para su ejercicio.

En general se podría identificar este aspecto del pensamiento sobre la subsidiariedad con la verticalid $\mathrm{d}^{47}$ de las relaciones entre distintos sujetos públicos y la decisión política de conferir competencias a aquéllos que se encuentran en una relación de cercanía territorial con los ciudadanos.

Como se puede ver, el principio de subsidiariedad aplicado a la organización pública no lleva consigo una relevante carga axiológica, motivo por el cual, en Italia, dicho aspecto del principio ha entrado en el ordenamiento jurídico sin provocar un escozor similar al causado cuando se comenzó a discutir sobre la introducción en la Constitución del principio de subsidiariedad como principio de organización social ${ }^{48}$.

Arribados a este punto, es posible advertir con claridad que el principio de subsidiariedad goza de variadas interpretaciones (liberalismo, doctrina social de la Iglesia, federalismo como sistema de organización política) así como de un vasto contenido axiológico.

Es precisamente por estas dos características que resulta interesante intentar analizar cómo esta polivalencia interpretativa y valórica del principio influye en su concepción y consagración positiva en los ordenamientos jurídicos que sirven de marco a este trabajo.

\section{APLICACIONES Y TIPOS}

Hemos dado una rápida revisión a los diversos orígenes del principio de subsidiariedad; esta multiplicidad de raíces no es baladí, por el contrario tiene una influencia decisiva en la polivalencia que le caracteriza y

${ }^{47}$ D'Atena, Antonio, Il principio di sussidiarietà, cit. (n. 42), p. 63: "Di qui, la difussa interpretazione del federalismo come tecnica di divisione verticale del potere".

${ }^{48}$ Precisamente por esta razón, es decir, como portador de una carga axiológica mucho más ligera, ha sido acogido sin grandes polémicas por parte del legislador italiano. MAssa PINTO, Ilenia, Il principio di sussidiarietà. Profili storici e costituzionali, cit. (n. 5), p. 59: "il dibattito sull'inserimento della sussidiarietà nella sua dimensione verticale non [ha] suscitato alcun contrasto di rilievo."[...] Albanese, Alessandra, $I l$ principio di sussidiarietà orizzontale: autonomia sociale e compiti pubblici, cit. (n. 17), p. 52: "La discussione, sia politica che scientifica, si è sviluppata prevalentemente con riferimento all'applicazione del principio quale regola di attribuzione delle competenze fra Stato e regioni, ed in quest'accezione (sussidiarietà verticale) [...] sembra essere entrata agevolmente anche nella cultura giuridica italiana e nella legislazione di riorganizzazione amministrativa". 
le es propia, todo lo cual se puede apreciar con claridad en las diferentes aplicaciones que tiene en los ordenamientos jurídicos contemporáneos.

1. La subsidiariedad en la Constitución italiana.

El interés en Italia sobre el principio de subsidiariedad surge con su inclusión en el Tratado Constitutivo de la Comunidad Europea ${ }^{49}$ el cual, en su artículo 5 (antiguo artículo 3B del Tratado de Maastricht), establece que "en los ámbitos que no sean de su competencia exclusiva, la Comunidad intervendrá, conforme al principio de subsidiariedad, sólo en la medida en que los objetivos de la acción pretendida no puedan ser alcanzados de manera suficiente por los Estados miembros, y, por consiguiente, puedan lograrse mejor, debido a la dimensión o a los efectos de la acción contemplada, a nivel comunitario".

En el Derecho interno italiano, por su parte, el principio de subsidiariedad ha ingresado por la puerta ancha a la Constitución ${ }^{50}$. Ya hemos dicho

${ }^{49}$ Massa Pinto, Ilenia, Il principio di sussidiarietà. Profili storici e costituzionali, cit. (n. 5), p. 27: "fu il Trattato di Maastricht, il trattato istitutivo dell'Unione europea nel 1992, a riportare alla luce un principio quasi del tutto dimenticato"; ALBANESE, Alessandra, Il principio di sussidiarietà orizzontale: autonomia sociale e compiti pubbli$c i$, cit. (n. 17), p. 51: "Il dibattito sul significato e sul valore del principio di sussidiarietà è in Italia piuttosto recente ed è stato suscitato soprattutto dall'introduzione di tale principio nel Trattato di Masstricht, che lo ha indicato come criterio di distribuzione delle competeze fra Unione europea e Stati membri"; D’Atena, Antonio, Il principio di sussidiarietà, cit. (n. 42), p. 59: el descubrimiento del principio de subsidiariedad, en Italia, "[...] è stata, tuttavia, una scoperta tardiva, la quale è concisa con l'elaborazione e con l'introduzione dell'artículo 3 B del Trattato di Maastricht (oggi, artículo 5 del Trattato CE)” (“[...] ha sido, sin embargo, un descubrimiento tardío, el cual ha coincidido con la elaboración y con la introducción del artículo 3 B del Tratado de Maastricht (hoy, artículo 5 del Tratado CE)").

${ }^{50}$ Desde la aprobación de la Constitución de 1948, la doctrina italiana discutió si este principio se encontraba implícitamente consagrado en aquellas normas (como el artículo $2^{\circ}$, inciso $\left.1^{\circ}, 5^{\circ}, 30\right)$ que reconocen las formaciones sociales, establecen la promoción de las autonomías locales o prescriben un criterio de preferencia a favor del derecho de los padres a educar a sus hijos. Las opiniones, por supuesto, son variadas: por ejemplo, D’Atena, Antonio, Costituzione e principio di sussidiarietà, cit. (n. 45), p. 24, sostiene que "[...] i costituenti italiani, pur non facendo uso de la parola "sussidiarietà", hanno adottato una serie di soluzioni ispirate al principio corrispondente. Il quale, quindi in relazione ad una pluralità di discipline, si presenta come un principio costituzionale non scritto".; igual opinión en D'ATENA, Antonio, Il principio di sussidiarietà, cit. (n. 42), p. 72. En cambio, MASSA PINTO, Ilenia, Il principio di sussidiarietà. Profili storici e costituzionali, cit. (n. 5), p. 57, es de la opinión que "in questa prospettiva è lecito se non altro dubitare che il principio di sussidiarietà debba essere considerato come implicito in tutte le norme costituzionali che si limitano a garantire forme di autonomia sociale (e, come si vedrà per le altre accezioni, territoriale)”. 
que la reforma constitucional introducida a través de la Ley constitucional No 3, de 2001, ha consagrado el principio de subsidiariedad (en su carácter horizontal, como veremos) en el artículo 118, inciso final, de la Constitución: "Regiones, Ciudades metropolitanas, Provincias y Municipios favorecen la autónoma iniciativa de los ciudadanos, individualmente o asociados, para el desarrollo de actividades de interés general, sobre la base del principio de subsidiariedad's1.

Al mismo tiempo, ha establecido una especie de federalismo (que, junto al sistema de autonomías español, es conocido con el nombre de "federalismo mediterráneo", para distinguirlo de las organizaciones federales del norte de Europa, in primis, el sistema alemán) en la organización interna de los poderes del Estado, al establecer que "corresponde a las Regiones la potestad legislativa en relación a todas las materias no expresamente reservadas a la legislación del Estado" (artículo 117 inciso 40) ${ }^{52}$ y que "las funciones administrativas corresponden a los Municipios salvo que, para asegurar el ejercicio unitario sean conferidas a las Provincias, Ciudades metropolitanas, Regiones y Estado, sobre la base de los principios de subsidiariedad, diferenciación y adecuación" (artículo 118 inciso 10 ${ }^{53}$. Finalmente se prevé en el artículo 120 la posibilidad que el poder central (el Gobierno) actúe subsidiariamente respecto del ente originalmente investido de la competencia: "El Gobierno puede sustituirse a los órganos de las Regiones, de las Ciudades metropolitanas, de las Provincias o de los Municipios en el caso de inobservancia respecto de normas y tratados internacionales o de la normativa comunitaria o también cuando lo requieran la tutela de la unidad jurídica o de la unidad económica y, en particular, la tutela de los niveles esenciales de las prestaciones concernientes a los derechos civiles y sociales, prescindiendo de los confines territoriales de los gobiernos locales. La ley definirá el procedimiento destinado a garantizar que

51 "Regioni, Città metropolitane, Province e Comuni favoriscono l'autonoma iniziativa dei cittadini, singoli e associati, per lo svolgimento di attività di interesse generale, sulla base del principio di sussidiarietà". Se hace necesario realizar un comentario sobre el modus legislativo italiano: la prescripción en la norma legal viene expresada en tiempo presente y no en imperativo, como es en nuestro país. Por ello, el 'verbo rector' de esta norma ('favorecen': 'favoriscono') debe ser leído como 'favorecerán' o 'deben favorecer'. La misma observación es válida para las demás normas italianas citadas.

52 "Spetta alle Regioni la potestà legislativa in riferimento ad ogni materia non espressamente riservata alla legislazione dello Stato".

53 "Le funzioni amministrative sono attribuite ai Comuni salvo che, per assicurarne l'esercizio unitario, siano conferite a Province, Città metropolitane, Regioni e Stato, sulla base dei principi di sussidiarietà, differenziazione ed adeguatezza". 
los poderes sustitutivos sean ejercidos respetando el principio de subsidiariedad y el principio de leal colaboración ${ }^{254}$.

Este es el cuadro normativo de nivel constitucional y supraconstitucional ${ }^{55}$ que los juristas italianos tienen a su disposición.

La positivización expresa del principio de subsidiariedad ha generado un fuerte interés en su estudio, lo que ha llevado a la doctrina a esforzarse en desentrañar el significado y las consecuencias que tiene esta consagración en el ordenamiento jurídico.

Ocupándonos de este aspecto, creemos que uno de los desarrollos más significativos que se puede encontrar en la doctrina italiana es la distinción y clara sistematización de las dos 'caras' de este principio, que corresponden a los dos ámbitos en los cuales la subsidiariedad tiene aplicación, es decir, como principio de organización social y como principio de organización político administrativa.

En efecto, como ya se había adelantado, la subsidiariedad aplicada a la organización político administrativa se identifica con los sistemas de repartición de competencias públicas: este es el sentido vertical del principio que nos ocupa. Por su lado, cuando el principio de subsidiariedad impacta la organización social, la delimitación de las tareas que corresponden al Estado y a la sociedad, le viene atribuido el carácter de horizontal.

El apelativo vertical viene aplicado a la subsidiariedad cuando una norma jurídica establece que sea la organización política o administrativa más cercana a la comunidad la que tenga competencia en un determinado asunto, materia o ámbito ${ }^{56}$. Este sentido de la subsidiariedad es el que se

54 "Il Governo può sostituirsi a organi delle Regioni, delle Città metropolitane, delle Province e dei Comuni nel caso di mancato rispetto di norme e trattati internazionali o della normativa comunitaria oppure di pericolo grave per l'incolumità e la sicurezza pubblica, ovvero quando lo richiedono la tutela dell'unità giuridica o dell'unità economica e in particolare la tutela dei livelli essenziali delle prestazioni concernenti i diritti civili e sociali, prescindendo dai confini territoriali dei governi locali. La legge definisce le procedure atte a garantire che i poteri sostitutivi siano esercitati nel rispetto del principio di sussidiarietà e del principio di leale collaborazione".

${ }^{55} \mathrm{La}$ calificación de "supraconstitucionalidad" que se hace respecto de los instrumentos pacticios del derecho comunitario no es gratuita. Se vea, por ejemplo, las recientes sentencias de la Corte constitucional italiana números 348 y 349 de 2007, por medio de las cuales se declaró la inconstitucionalidad de normas de derecho interno tomando como base normas de derivación comunitaria.

${ }^{56}$ Véase: por ejemplo, Ferroni, Maria Victoria, Principio di sussidiarietà e negoziazione urbanistica (Torino, Giappichelli, 2008), p. 10: "A seconda del livello e del grado di relazione, il principio di sussidiarietà opera in senso diverso: [...] "verticale", nei rapporti tra pubblici poteri (intesi come enti pubblici territoriali), situati a livelli diversi delimitando le sfere di competenza spettanti, appunto, ai diversi livelli istituzionali”; BerTOLInI, Cecilia, La sussidiarietà amministrativa, ovvero la progres- 
puede observar en los Estados de organización federal - como Alemania ${ }^{57}$ - en los cuales son los estados federados (los "Länder") los titulares de las competencias generales, siendo excepcional la competencia del Estado federal, es decir, de aquella organización política espacialmente más lejana de los ciudadanos. Esta es la acepción consagrada por el artículo 118 inciso $1^{\circ}$, de la Constitución italiana ${ }^{58}$, al establecer que las funciones administrativas corresponden a los Municipios, salvo que para asegurar su ejercicio unitario sea necesario conferirlas a las Provincias, a las Ciudades metropolitanas, a las Regiones o al Estado.

En cambio, el apelativo horizontal es predicado respecto del principio de subsidiariedad cuando éste se transforma en un principio de organización social ${ }^{59}$, es decir, cuando prescribe la precedencia ontológica de

siva affermazione di un principio, en Diritto Amministrativo (2007), p. 905: “[...] il principio di sussidiarietà esprime le proprietà distributive che gli sono proprie secondo la proiezione geometrica verticale, operando nel rapporti tra i diversi liveIli istituzionali"; PICOZZA, Eugenio, Introduzione al diritto amministrativo, (Padova, Cedam, 2006), p. 114: "il principio [...] postula che le decisioni prese normalmente dal centro di potere politico più collegato alla comunità di riferimento e cioè dal Comune, dalla Provincia, dalla Regione, ecc. Tale sussidiarietà viene denominata "verticale", perché si collega all'asse dei rapporti costituzionali tra gli enti territoriali che compongono la Repubblica"; D’Andrea, Antonio, La prospettiva della Costituzione italiana ed il principio di sussidiarietà, en Jus (2000) p. 228: "La sussidiarietà di tipo verticale investe gli assetti territoriali relativi ad un determinato ordinamento giuridico (ed in primo luogo gli Stati federali) in riferimento all'esercizio delle funzione pubbliche e consiste nell'assegnare tali funzioni partendo dall'Ente più vicino ai consociati, ipotizzando l'esercizio -sussidiario- delle funzioni da parte degli Enti di ambito e dimensione più ampi (e perciò più lontani dai consociati) solo quando non sia efficace né economicamente conveniente l'azione dell'Ente di primo o secondo livello".

${ }^{57}$ El artículo 30 de la Ley Fundamental de la República Federal Alemana (Grundgesetz) establece que "el ejercicio de las competencias estatales y el cumplimiento de las funciones estatales competen a los Länder siempre que la presente Ley Fundamental no disponga o admita una disposición en contrario".

${ }^{58}$ Véase: D’Atena, Antonio, Dimensioni e problemi della sussidiarietà, en DE Martin Gian Candido (editor), Sussidiarietà e democrazia. Esperienze a confronto e prospettive (Padova, Cedam, 2008), p. 39: "La declinazione verticale è contemplata dall'artículo 118, comma 1, Cost. il quale dopo aver attribuito ai Comuni la competenza amministrativa generale, ammette spostamenti verso l'alto di funzioni in essa compresse, sulla base -tra l'altro- del principio di sussidiarietà" ("la declinación vertical se encuentra contemplada en el artículo 118 , inciso $1^{\circ}$, de la Constitución, el cual - después de haber atribuido a las comunas la competencia administrativa general - admite desplazamientos hacia niveles superiores de funciones en ella comprendidas, sobre la base - entre otras - del principio de subsidiariedad").

${ }^{59}$ Motivo por el cual, alguna doctrina lo denomina precisamente de este modo: principio di subsidiariedad social. Véase: Camerlengo, Quirino, Articolo 118, en 
la sociedad civil respecto del poder público en la realización de tareas de interés público. En otros términos, bajo esta perspectiva, el principio de subsidiariedad se transforma en un criterio de división de competencias entre lo público, el Estado, y la sociedad civil.

Teniendo como base esta distinción bipartita, la doctrina italiana ha elaborado una sistematización más compleja que distingue entre subsidiariedad horizontal constitucional y administrativa, y subsidiariedad vertical, a su vez también, constitucional y administrativa ${ }^{60}$.

Lasubsidiariedad horizontal en sentido constitucional pretende otorgar una respuesta específica al rol del poder público respecto a la organización social. Según esta acepción, el ejercicio de funciones estatales es legítimo solamente si se encuentra orientado a hacer frente a la eventual inadecuación de los individuos o de sus organizaciones. En suma, se trata de la concepción más clásica de la subsidiariedad y que nuestra doctrina estima vigente en la disciplina constitucional chilena, como veremos más adelante.

La subsidiariedad horizontal en sentido administrativo se refiere al "empleo de la fórmula lexical principio de subsidiariedad cuando, en la relación administrados-administración [...], [se] prescribe la preferencia por los primeros en lugar de la segunda”. En esta acepción el principio "impone a las instituciones públicas de organizarse y ejercitar las funciones de que son titulares de manera tal de favorecer la participación de los administrados" ${ }^{61}$ y por ello se puede afirmar que sea una manifestación del principio democrático del Estado de Derecho.

La subsidiariedad vertical en sentido constitucional, por su parte, se relaciona con aquella preferencia que debería ser establecida a los representantes más vecinos a los representados (ciudadanos) con el fin de individualizar el nivel de gobierno competente para el ejercicio de una función determinada. Es, en otras palabras, un criterio para dirigir la atribución de funciones a favor de los representantes que actúan en los niveles de gobierno más cercanos a los ciudadanos ${ }^{62}$ y que se manifiesta

Bifulco, Raffaele - Celotto, Alfonso - Olivetti, Marco (editores), Commentario alla Costituzione (Milano, Giuffrè, 2006) III, p. 2350: "La riforma costituzionale ha consacrato anche la dimensione normalmente definita "orizzontale" del principio di sussidiarietà, in quanto relativa ai rapporti tra i pubblici poteri e la comunità. In via preliminare $[. .$.$] si predilige la distinzione tra sussidiarietà istituzionale e sussidiarietà$ sociale".

${ }^{60}$ Sobre esta elaboración, MASSA PINTO, Ilenia, Il principio di sussidiarietà, cit. (n. 5), p. 41 y ss. En esta parte del trabajo seguimos las ideas expresadas por la autora.

${ }^{61}$ Ibíd., p. 135.

${ }^{62}$ Ibíd., p. 66. 
con claridad en los sistemas de organización federal, donde, precisamente, se encuentra el origen de esta concepción.

Finalmente, la subsidiariedad vertical en sentido administrativo, es aquella que establece el modo en el cual el nivel de gobierno ya individualizado por aplicación de la subsidiariedad vertical en sentido constitucional (es decir, el nivel de gobierno más cercano al ciudadano) debe ejercer las competencias que se le han atribuido. En otros términos, se trata de otorgar una preferencia a la Administración más cercana a los ciudadanos en modo tal que ésta pueda involucrarlos en sus procedimientos de adopción de las decisiones que son de su competencia y cuyos efectos recaerán, precisamente, en ellos ${ }^{63}$.

En Italia, como se puede apreciar, existe plena conciencia que el principio de subsidiariedad no significa solamente el retraimiento del Estado de la vida social o, en otras palabras, un "Estado mínimo". Por el contrario, el principio de subsidiariedad es entendido como un concepto flexible que sirve a orientar la modalidades de actuación pública e, incluso, puede llegar a estimular y exigir la intervención del Estado en la vida social. Por otro lado, la progresiva introducción de un sistema de organización administrativa de tipo federalista (principalmente como consecuencia de las modificaciones introducidas por la ya mencionada Ley constitucional No 3 del 2001) demuestran una clara intención del Constituyente de ir entregando mayor competencia y autonomía a aquellas entidades políticas que se encuentran en una relación de cercanía espacial con los ciudadanos.

Por ello, dice la doctrina italiana ${ }^{64}$, el principio de subsidiariedad, si bien postula el respeto de la libertad de los individuos y de los grupos intermedios que surgen en la sociedad, no pone en discusión el rol y la importancia del Estado, lo que no quiere decir que no se prevea una redefinición y racionalización de su rol en las dinámicas de las relaciones entre el público y el privado: el Estado se alza como garante final del interés público, puesto que a éste corresponde la intervención decisiva cuando se demuestre que el privado no es capaz de hacerse cargo de una necesidad cuya relevancia social hace impostergable su satisfacción.

La doctrina italiana, en suma, es consciente acerca de la circunstancia

${ }^{63}$ Utilizando una nomenclatura ligeramente distinta, BERTOLINI, Cecilia, La sussidiarietà amministrativa, ovvero la progressiva affermazione di un principio, cit. (n. 56), p. 905, señala que la subsidiariedad administrativa es un tipo de subsidiariedad vertical, "[...] poiché determina la allocazione generale delle funzioni all'ente inferiore e consente l'intervento dell'ente superiore nei casi in cui l'ente subordinato non abbia le capacità o le risorse necessarie per soddisfare un pubblico interesse".

${ }^{64}$ Frosini, Tommaso Edoardo, Sussidiarietà (Principio di) (Dir. cost.), cit. (n. 23), p. 1.139. 
que el principio de subsidiariedad se encuentra lejos de evocar escenarios de "privatización salvaje" ${ }^{65}$, ya que, de hecho, no exige un indiscriminado retiro del Estado; simplemente, funcionaliza su actuación, admitiéndola en todos aquellos casos en los cuales el 'privado' no sea suficiente o adecuado a la satisfacción de una determinada tarea de interés público. Si se aprecia cuidadosamente, el principio así leído, al contrario de negarla, reafirma la necesidad de lo público.

De cualquier manera, en Italia no podría ser de otro modo dada la importancia clave del Estado en la prestación de numerosos servicios asistenciales, por efecto de la configuración social que le fue atribuido por la Constitución, la cual garantiza a los ciudadanos la igualdad sustancial (artículo 2), el acceso a las prestaciones y curas médicas (artículo 32), la instrucción pública (artículo 34), la asistencia social para quien es incapaz de trabajar (artículo 38), etc.

Para concluir, debemos señalar que, en su conjunto, la doctrina italiana ha mostrado un notable entusiasmo acerca del principio lo cual se ha manifestado en una prolífica producción científica ${ }^{66}$. Ésta ha ayudado

${ }^{65}$ Expresión de D’Atena, Antonio, Costituzione e principio di sussidiarietà, cit. (n. 45), p. 29.

${ }^{66}$ La bibliografía sobre esta materia alcanza el carácter de inabordable. Entre lo esencial se puede citar a: AlBANESE, Alessandra, Il principio di sussidiarietà orizzontale: autonomia sociale e compiti pubblici, en Diritto Pubblico (2002); ANTONInI, Luca, Il principio di sussidiarietà orizzontale: da Welfare State a Welfare Society, en Rivista di Diritto Finanziario e Scienza delle Finanze (2000); ARENA, Gregorio, Il principio di sussidiarietà orizzontale nell'artículo 118 u.c. della Costituzione, en Studi in onore di Giorgio Berti, (Napoli, Jovene, 2005), I; BALESTRERI, Adolfo Mario, Sussidiarietà, territorio, cooperazione fra mano pubblica e soggetti privati. Spunti per un inquadramento giuridico, en Diritto Amministrativo (1998); BerTOLInI, Cecilia, La sussidiarietà amministrativa, ovvero la progressiva affermazione di un principio, en Diritto Amministrativo (2007); CASSESE, Sabino, L'aquila e le mosche. Principio di sussidiarietà e diritti amministrativi nell'area europea, en Il Foro Italiano (1995); D'AlEssANDro, Daniele, Sussidiarietà, solidarietà e azione amministrativa (Milano, Giuffrè, 2004); D'ANDREA, Antonio, La prospettiva della Costituzione italiana ed il principio di sussidiarietà, en Jus (2000); D'AtenA, Antonio, Costituzione e principio di sussidiarietà, en Quaderni Costituzionali (2001); D'Atena, Antonio, Dimensioni e problemi della sussidiarietà, en De MARTIN, Gian Candido (editor) Sussidiarietà e democrazia. Esperienze a confronto e prospettive (Padova, Cedam, 2008); D’ATENA, Antonio, Il principio di sussidiarietà, en El MIsmo Lezioni di Diritto costituzionale (Torino, Giappichelli, 2001); D'AtenA, Antonio, Il principio di sussidiarietà nella Costituzione italiana, en Rivista Italiana di Diritto Pubblico Comunitario (1997); D’ATENA, Antonio, La sussidiarietà tra valori e regole, en Diritto e Giurisprudenza Agraria e dell'Ambiente (2004); Deaglio, Mario, Sussidiarietà, istituzioni economiche, imprese, en QuAdrIo CuRZIO, Alberto - ForTIS, Marco (editores), Valorizzare un'economia forte. L'Italia e il ruolo della sussidiarietà, (Bologna, Il Mulino, 2007); De CARLI, Paolo, Sussidiarietà e governo economico (Mi- 
a comprender que el principio que nos ocupa no trae consigo la 'desaparición' del Estado como actor de la vida social y económica, sino que su redimensionamiento para actuar como sostén de la libertad e iniciativa individual.

Si esto se ha hecho realidad, en los ya ocho años de 'existencia' de este principio, es muy pronto para decirlo.

lano, Giuffrè, 2002); DE CARLI, Paolo, Sussidiarietà: tra il dire e il fare, en Studi onore di Giorgio Berti, (Napoli, Jovene, 2005), II; Del Prato, Enrico, Principio di sussidiarietà e regolazione dell'iniziativa economica privata. Dal controllo statale a quello delle autorità amministrative indipendenti, en Rivista di Diritto Civile (2008); DE MARTIN, Gian Candido (editor), Sussidiarietà e democrazia. Esperienze a confronto e prospettive (Padova, Cedam, 2008); Duret, Paolo, La sussidiarietà orizzontale: le radici e le suggestioni di un concetto, en Jus (2000); DuRET, Paolo, Sussidiarietà e autoamministrazione dei privati, (Padova, Cedam, 2004); Ferroni, Maria Victoria, Principio di sussidiarietà e negoziazione urbanistica, (Torino, Giappichelli, 2008); Franzese, Lucio, Ordine economico e ordinamento giuridico: la sussidiarietà delle istituzioni (2a Padova, Cedam, 2006); Frosins, Tommaso Edoardo, Profili costituzionali della sussidiarietà in senso orizzontale, en Rivista giuridica del mezzogiorno (2000); FrosinI, Tommaso Edoardo, Sussidiarietà (Principio di) (Dir. cost.), en Enciclopedia Giuridica (Milano, Giuffrè, 2008); GÖTZ, Volkmar - HeCKER, Michael, Il principio di sussidiarietà nel Diritto costituzionale tedesco con particolare riferimento alla sua dimensione federale, en Rinella, Angelo - Coen, Leopoldo; Scarciglia, Roberto - Mistò, Michele (editores) Sussidiarietà e ordinamenti costituzionali. Esperienze a confronto, (Padova, Cedam, 1999); Massa PinTo, Ilenia, Il principio di sussidiarietà. Profili storici e costituzionali, (Napoli, Jovene, 2003); Millon-Delsol, Chantal, Il principio di sussidiarietà, (traducción italiana de Tringalli, Massimo (Milano, Giuffrè, 2003); Moscarini, Anna, Sussidiarietà e libertà economiche, en Diritto e Società (1999); NinATTI, Stefania, Interventi pubblici nell'economia tra mercato unico e principio di sussidiarietà. Orientamenti della giurisprudenza comunitaria e della dottrina tedesca, en Rivista Italiana di Diritto Pubblico Comunitario (1996); PASTORI, Giorgio, Amministrazione pubblica e sussidiarietà orizzontale, en Studi in onore di Giorgio Berti, (Napoli, Jovene, 2005), II; PASTORI, Giorgio, Sussidiarietà e Diritto alla salute, en Diritto Pubblico (2002); PoGgI, Annamaria, Il principio di sussidiarietà e il "ripensamento" dell'amministrazione pubblica (2005), accedido 30 enero 2009 en, www.astrid-online.it; QUADRIO CURZIO, Alberto, Riflessioni sul liberalismo comunitario per lo sviluppo italiano, en QUADRIO Curzio, Alberto - Fortis, Marco (editores), Valorizzare un'economia forte. L'Italia e il ruolo della sussidiarietà, (Bologna, Il Mulino, 2007); RAzZANO, Giovanna, Le fonti del diritto e il principio di sussidiarietà nel quadro dei più recenti interventi legislativi per la «semplificazione», en Diritto Amministrativo (2001); RESCIGNO, Giuseppe Ugo, Principio di sussidiarietà orizzontale e diritti sociale, en Diritto Pubblico (2002); RESCIGNO, Giuseppe Ugo, Stato sociale e principio di sussidiarietà, en Quaderni Regionali (2002); Rinella, Angelo - Coen, Leopoldo - Scarciglia, Roberto - Mistò, Michele (editores), Sussidiarietà e ordinamenti costituzionali. Esperienze a confronto, (Padova, Cedam, 1999). 


\section{El principio de subsidiariedad en Chile.}

Nuestro país goza de una mayor 'experiencia' en esta materia. El principio de subsidiaridad-que se encontraría consagrado en el artículo 1 inciso $3^{\circ}$, C.Pol.- ha sido reconocido por la doctrina como uno de los pilares de la institucionalidad establecida por la Constitución de 1980, lo que se ha traducido en la convicción de que este principio debe regir la actuación del Estado en materia económica, identificándose el fundamento normativo de ello en el artículo 19 № 21 C.Pol., norma que traería su inspiración, precisamente, del artículo 1 inciso $3^{\circ}$ C.Pol..

Creemos, sin embargo, que el análisis que se ha hecho sobre este principio no recoge su viva evolución y, sobre todo, desatiende su vasta riqueza axiológica.

En efecto, prácticamente no existe disenso en nuestra doctrina ${ }^{67}$ en

${ }^{67}$ Aróstica Maldonado, Iván, Crónica sobre la expansión del estado empresario y el retraimiento de la iniciativa privada, en Ius Publicum 2 (1999), p. 129: "sólo por excepción el Estado puede asumir cometidos empresariales, si se satisfacen los requisitos definidos por el principio de subsidiariedad (artículo 1 incisos $1^{\circ}$ y $3^{\circ}$ )"; BAUER, Carl, Derecho y economía en la constitución de 1980, cit. (n. 40), p. 31: "Las provisiones económicas en la Constitución son breves, pero fundamentales. Establecen lo que se denomina el "orden público económico", que consiste en amplios derechos económicos privados que van acompañados de fuertes limitaciones a las actividades económicas y poderes regulatorios del Estado. La médula de esta provisiones se encuentra en el artículo 19, que enumera todos los derechos constitucionales (específicamente los números 21 a 26), los cuales, junto con el artículo 1, expresan el principio del "Estado subsidiario" aun cuando el término no es mencionado explícitamente"; BERTELSEN REPETTO, Raúl, El estado empresario en la Constitución de 1980, en Revista Chilena de Derecho 14 (1987), p. 123: "Es indudable, si interpretamos el número 21, del artículo 19, en el conjunto de sus dos incisos, en relación con otras normas constitucionales como el artículo $1^{\circ}$, que consagra la autonomía de los grupos intermedios y precisa la finalidad y deberes del Estado, y a la luz de sus antecedentes en que se afirma expresamente, que dicho precepto es el medio a través del cual se ha hecho operar el principio de subsidiariedad en el plano económico"; Bulnes Aldunate, Luz, Visión académica de la Constitución económica de 1980, en Revista de Derecho Público 62 (2000), p. 90: "El capítulo I de la Constitución de 1980 , se pronuncia abiertamente por el reconocimiento del principio de subsidiariedad del Estado"; Covarrubias Cuevas, Ignacio, El principio de subsidiariedad, cit. (n. 26), p. 74: "[...] del estudio de la historia fidedigna del establecimiento de la disposiciones que consagran este principio [artículos $1^{\circ}$ inc. $3^{\circ}$ y 19 n. 21 . N. del A.] se observa nítidamente su recepción por la Carta Fundamental”; SAN FrANCISCO REYES, Alejandro, Jaime Guzmán y el principio de subsidiariedad educacional, en la Constitución de 1980, cit. (n. 24), p. 543: "Dentro de las bases de la institucionalidad chilena, el constituyente de 1980 consagra el principio de subsidiariedad: artículo 1 inc. 30"; TAPIA VALDÉS, Jorge, Descentralización y subsidiariedad en la época de la globalización, en Revista del Centro de Estudios Constitucionales de Chile 1 (2003), p. 101: "Otra 
cuanto a que el principio de subsidiariedad ha sido consagrado en el artículo 1 inciso 3, C.Pol. que, como sabemos, establece que "El Estado reconoce y ampara a los grupos intermedios a través de los cuales se organiza y estructura la sociedad y les garantiza la adecuada autonomía para cumplir sus propios fines especificos".

De la misma manera, se ha visto una manifestación de este principio en la disposición del artículo 19 No 21 C.Pol. que regula, como es bien sabido, la libertad de iniciativa privada en materia económica y la actuación del Estado en actividades empresariales (régimen, generalmente denominado, del Estado empresario).

Como bien sabemos, nuestro ordenamiento jurídico no cuenta con una disposición constitucional expresa que consagre este principio, a diferencia de cuanto ocurre sea en la Unión europea (en el ya mencionado artículo 5 del Tratado Constitutivo de la Unión), sea en Italia (artículos 117, 118 incisos $1^{\circ}$ y $4^{\circ}$ y 120 de la Constitución).

¿Significa, entonces, que la nutrida doctrina que reconoce presente el principio en los artículos 1 inciso $3^{\circ}$ y 19 No 21 , se encuentra equivocada? ${ }^{68}$.

perspectiva es la que distingue entre sentidos vertical y horizontal de la subsidiariedad. El primero está referido a la definición de relaciones y división de competencias entre Estado (sociedad política) y sociedad civil, y es el que principalmente fue acogido por la Constitución chilena de 1980 en su artículo $1^{\circ}$ inciso tercero"; VARELA DEL SOLAR, Jorge, Subsidiariedad, orden público económico y seguridad nacional en la Constitución de 1980, en Revista Chilena de Derecho 16 (1989), p. 381: "En efecto, la subsidiariedad se aloja según mi opinión no solamente en el inciso tercero (del artículo $1^{\circ}$ C.Pol., n. del a.), en inseparable armonía con la noción de grupos o cuerpos intermedios, encargados por la Constitución de ejercer la primariedad en contrapunto con el Estado-Gobierno [...]".

${ }^{68} \mathrm{Al}$ menos esta es la opinión de Ruiz-Tagle Vial, Pablo, Principios constitucionales del Estado empresario, cit. (n. 30), p. 56: "El principio de subsidiariedad es considerado por varios autores como vinculado a la disposición constitucional del artículo 19 número 21, pero en nuestra opinión no alcanza una formulación clara y unívoca desde el punto de vista de origen teológico, y por eso no puede ser considerado como un principio que tiene un contenido estable en nuestro derecho constitucional"; de Vallejo Garreton, Rodrigo - Pardow Lorenzo, Diego, Derribando mitos sobre el estado empresario, cit. (n. 1), p. 137, quienes explican que es a causa de una interpretación conservadora operada por posiciones iusfundamentales que se ha aceptado la idea que el principio de subsidiariedad se encuentra reconocido por nuestra Carta constitucional; y de SchÜrmann, Miguel, Orden público económico y principio de subsidiariedad, argumentos para una crítica, cit. (n. 1), págs. 10 ss., quien sostiene que el principio de subsidiariedad podría estar consagrado en la norma del artículo 19 n. 21 de la C.Pol., pero que ello dependerá de una necesaria interpretación ius naturalista cristiana de la norma. En otras palabras, el autor sostiene que el principio de subsidiariedad es sólo una de las posibilidades interpretativas de 
Creemos que no; al menos en parte.

En primer lugar, creemos que el principio de subsidiaridad es, innegablemente, la fuente inspiradora de la disposición del artículo 1 inciso 3o, C.Pol.. Los antecedentes de la norma constitucional lo confirman ampliamente ${ }^{69}$ al tiempo que el texto expreso no deja mucho campo para una interpretación diversa, ya que podemos apreciar en él la presencia de los elementos esenciales de la elaboración doctrinal de la Iglesia católica sobre este principio, a saber, in primis, el reconocimiento y protección de los cuerpos intermedios, el reconocimiento de que ellos constituyen la base sobre la cual se estructura y organiza la sociedad política, y la garantía de libertad y protección para el cumplimiento de sus fines específicos. Por ello, creemos que la doctrina que identifica en el artículo 1 inciso $3^{\circ}$, C.Pol. una manifestación de algunos de los elementos centrales del principio de subsidiariedad se encuentra ampliamente justificada en sus razones.

Sin embargo, y por otro lado, opinamos, que la distancia entre afirmar que un precepto normativo tiene su inspiración en un principio y que un principio se encuentra consagrado en dicho precepto, es mucha. Esta distancia es aún mayor si lo que se pretende es extraer un principio

la norma, no siendo posible, en consecuencia, sostener que indudablemente se encuentra presente en ella.

${ }^{69}$ Sobre el punto, véase, entre otros: Sото KLoss, Eduardo, La actividad económica en la Constitución Politica de la República de Chile (La primacía de la persona humana), en Ius Publicum 2 (1999), p. 120; Bauer, Carl J., Derecho y economía en la constitución de 1980, cit. (n. 40), p. 28: "Los gremialistas apuntaban a resguardar la autonomía de los grupos intermedios de la interferencia del Estado, siempre que evitaran la política. Ellos también adoptaron, de la doctrina social católica, el principio de Estado subsidiario"; Covarrubias Cuevas, Ignacio, El principio de subsidiariedad, cit. (n. 26), p. 73: “[...] el propio presidente de la CENC, refiriéndose a una de las disposiciones más relevantes de la Constitución política en materia económica, el artículo 19 n. 21 afirmaba que: "sin lugar a dudas [...] la excepción contemplada en esta parte tiene la virtud de reafirmar el principio de subsidiariedad. [...] cabe señalar que tanto el memorándum enviado por el Presidente de la República titulado "Orientaciones para la Comisión de Estudios de la Nueva Constitución" como en el Informe del Consejo de Estado, se expresa que las normas establecidas en el artículo 19 n. 21 como la del artículo $1^{\circ}$ inciso $3^{\circ}$ deben "reconocer el principio de subsidiariedad conforme al cual el Estado hace lo que los particulares son incapaces de hacer, respetando y haciendo posible la iniciativa privada". Específicamente en relación con el artículo 19 n. 21 C.Pol., véase: HuIDOBRo SALAS, Ramón, El derecho a desarrollar cualquier actividad económica en las actas de la Comisión de estudios de la nueva constitución, en Revista de Derecho Público 43-44 (1988), págs. 113 ss. donde, citando la intervención del comisionado J. Guzmán en la sesión 388 de la CENC, se indica que éste señalo "[...] que el objetivo del precepto era más modesto, en el sentido que no se pretendía por sí solo configurar todo el principio, sino que colocar un eslabón que junto a otros, dejara sólidamente afirmada la subsidiariedad". 
no escrito a partir de la fuente inspiradora de un precepto y elevar ese 'principio no escrito', extrapolado de aquella fuente, a la categoría de regla jurídica.

Creemos que la interpretación que se ha hecho del artículo 19 No 21 adolece de esta falencia puesto que ha sido tradicionalmente aceptado que la disciplina establecida en dicha norma se basa en el principio de subsidiariedad 'establecido' en el artículo 1 inciso $3^{\circ}$ C.Pol.

Opinamos que ello no es correcto, por dos razones: la primera, textual, y la segunda, sustancial.

La razón textual dice relación, evidentemente, con el hecho que ni esa norma, ni ninguna otra, menciona al principio de subsidiariedad, cosa que -como hemos visto más arriba- es perfectamente posible y de hecho ocurre en otros ordenamientos jurídicos, como el ordenamiento de la Unión Europea y el italiano. El principio de subsidiariedad deja de ser, por ello, sólo un principio de actuación política del poder público para convertirse en una disposición de Derecho positivo, cosa que no se advierte en nuestro ordenamiento constitucional.

La razón sustancial, por su lado, es que el principio de subsidiariedad -al menos en su matriz de derivación católica, que es aquella que inspiró la redacción del artículo 1 C.Pol.- está lejos de prescribir que el Estado debe abstenerse de desarrollar actividades económicas o que se deben imponer condiciones jurídicas más rigurosas para admitir que ello suceda, materia que es, precisamente, el contenido central del No 21 del artículo 19 C.Pol.

En efecto, si se revisa bien el artículo citado, podemos ver que contiene dos prescripciones: en el inciso $1^{\circ}$, se establece a favor de toda persona la libertad de desarrollar cualquier actividad económica, norma que dentro del sistema de la Constitución es el simple corolario del conjunto de otras libertades individuales consagradas en ella. En el inciso $2^{\circ}$, por su lado, se establece un régimen que debe ser observado por el Estado (lo público) para acometer el desarrollo de actividades empresariales o participar en ellas.

Nuestra tesis es que los postulados normativos en los cuales la doctrina nacional reconoce la presencia del principio de subsidiariedad (artículos 1 inciso $3^{\circ}$ y 19 No 21 y, especialmente, ellos en su conjunto) han sido leídos de un modo excesivamente rígido, extrapolando e identificando en ellas un verdadero principio de no intervención del Estado que ha sido confundido con el principio de subsidiariedad. En otras palabras, la postura doctrinaria más tradicional pretende ver una manifestación del principio de subsidiariedad donde no la hay, deformando, por consiguiente, el concepto mismo del principio, alterando con ello el sentido 
de la norma jurídica que se obtiene de la lectura del artículo 19 No 21 C.Pol. ([...] ).

Conviene aclarar inmediatamente que no estamos negando la presencia de los elementos caracterizadores del principio de subsidiariedad en nuestra Carta Fundamental. Sería, como hemos señalado más arriba, prácticamente imposible poner en discusión la decisiva influencia que este principio tuvo en la redacción de de los artículos 1 inciso $3^{\circ}$ y 19 No 21 C.Pol. o, mejor dicho, la decisiva influencia que tuvo en los redactores de estas normas.

Sin embargo, lo que sí se quiere destacar es que el vivo desarrollo que ha tenido este principio en el Derecho comparado no ha sido recogido cabalmente por nuestra evolución doctrinal, la cual se ha detenido a acentuar el carácter negativo, abstencionista del principio, especialmente en relación con la presencia del Estado en la economía y en la prestación de servicios sociales y de interés general. Esta interpretación no se conforma con los orígenes del principio de subsidiariedad de matriz católica que es, como hemos dicho más arriba, aquella que influyó en los redactores de la carta constitucional ${ }^{70}$ y que es clara fuente inspiradora del artículo 1 inciso $3^{\circ}$, C.Pol..

Según nuestra opinión, esta carencia interpretativa se aprecia con toda claridad en la exégesis que se hace del artículo 19 No 21 C.Pol., la cual olvida, sobre todo, el carácter esencialmente flexible o elástico del que goza el principio. Creemos que esta norma se limita a procedimentalizar la toma de decisiones políticas referentes a la presencia estatal en la realización de actividades empresariales. Si se lee con atención el precepto, podremos ver que él nada dice acerca de la subsidiariedad, como sí lo hace, por ejemplo, el artículo 60 de la Constitución del Perú ${ }^{71}$, ni establece criterios para decidir cuándo, por qué y bajo cuáles presupuestos de hecho el Estado podría interesarse a desarrollar actividades económicas y cuándo sería constitucionalmente legítimo que ello ocurriera.

Por ello cabe preguntarse una vez más, ¿qué dispone el artículo 19 № 21, inciso $2^{\circ}$ C.Pol.?

Establece, en primer lugar, que el Estado puede desarrollar o participar en actividades empresariales si una ley de quórum calificado lo autoriza.

En segundo lugar, que el desarrollo de esa actividad por parte del Estado

\footnotetext{
${ }^{70}$ Se vea sobre el pensamiento de J. Guzmán E. y su influencia en la redacción del artículo $1^{\circ}$ C.Pol. a Fontaine Talavera, Arturo, El miedo y otros escritos. El pensamiento de Jaime Guzmán Errázuriz, en Revista Estudios Públicos 42 (1991).

${ }^{71}$ Este punto ha sido atentamente recogido por VALLejo GarReTON, Rodrigo -; Pardow Lorenzo, Diego, Derribando mitos sobre el estado empresario, cit. (n. 1), p. 138 , nota 8 .
} 
debe estar sometida al régimen común aplicable a los particulares. Se agrega una excepción: una ley de quórum calificado puede autorizar un régimen especial o diverso del generalmente aplicable a los particulares.

Esta norma no dice nada más. Y, lo más relevante, es que no dice nada en relación con el principio de subsidiariedad. Por lo tanto, es legítimo plantear la siguiente interrogante: ¿se plasmó en esta norma el núcleo de este principio? o, en otras palabras ¿se funda esta norma en el principio de subsidiariedad?

Para encontrar una respuesta creemos necesario recordar lo que hemos señalado a lo largo de este trabajo: el núcleo esencial del principio de subsidiariedad, de acuerdo con la doctrina social de la Iglesia, consiste, en primer lugar, en el deber de respeto por parte del Estado (lo público) de la libertad y la iniciativa de los particulares (lo privado) y de las comunidades que surgen al interior de la sociedad (los cuerpos intermedios); en segundo término, que el Estado no debe realizar aquellas actividades que estas comunidades intermedias son capaces de llevar adelante, $\mathrm{y}$ finalmente que, si se detecta la insuficiencia de las comunidades intermedias para la satisfacción de una necesidad socialmente relevante -es decir, que puede ser considerada como una cuestión de carácter público-debe ser el Estado quien asuma su ejecución. Este deber se basa en el propio contenido del principio de subsidiariedad el cual es modelado por el principio y deber de solidaridad (que, en nuestro país se manifiesta en el artículo 1 inciso $4^{\circ}$, C.Pol.). Podemos ver que nada de esto se puede extraer de la norma del artículo 19 № 21 , inciso $2^{\circ}$.

A lo anterior debemos agregar que el principio de subsidiariedad ha dejado de ser sólo una idea ética o de filosofía política carente de un perfil claro a nivel jurídico. La evolución que este principio ha tenido fuera de las fronteras de nuestro país ha permitido que él se convierta en norma jurídica, es decir, en Derecho positivo vigente lo que manifiesta toda la flexibilidad del principio. La consecuencia inmediata de la positivización del principio ha sido, al menos a nivel de la Unión Europea, la creación de procedimientos orientados a verificar cuándo se presentan las condiciones que harían procedente la actuación por parte de aquella entidad (subsidiante) que debe sostener o ayudar a aquella otra que, siendo en primera instancia competente para la realización de una acción, no puede o es incapaz de llevarla a cabo (subsidiada).

Otra disciplina que da cuenta de la flexibilidad del principio y se encuentra orientada al mismo fin, es decir, a la definición de cuándo es procedente la actuación por parte de la entidad subsidiante, la podemos encontrar en las Gemeindeordnung alemanas, en particular aquella de la Baviera. El artículo 87 de la Bayerische Gemeindeordnung, establece 
los presupuestos de hecho que autorizan la actuación del municipio en actividades empresariales. En lo fundamental, impone requisitos que deben ser verificados por la Administración en forma previa a la adopción de la decisión de crear una empresa de propiedad comunal (o sea, de propiedad pública). Creemos que el más importante de esos requisitos, a los fines de este trabajo, sea el consagrado en el párrafo 1,4 que establece que "el municipio puede crear, adquirir o ampliar una empresa conforme al artículo 86, cuando: 4. las actividades ajenas a las funciones asistenciales del municipio no puedan ser desarrolladas con igual calidad y economicidad por otros sujetos" ". Podemos ver que la norma obliga a la Administración a efectuar un control sobre la procedencia de una actuación que, en primer término se encuentra reservada a los particulares pero que, de frente a la mayor calidad y economicidad de la actuación pública (en otras palabras, frente a la incapacidad de los privados), puede de todos modos desarrollar.

Como podrá haber sido ya advertido, creemos que ninguno de los elementos caracterizadores del principio de subsidiariedad se encuentra plasmado en la norma del artículo 19 No 21, y mucho menos se aprecia una elección a favor del privado que deba ser respetada por el Estado hasta el momento en que éste constate la incapacidad o inadecuación del primero en el desarrollo de una determinada tarea de relevancia o interés social o público. En otras palabras, el artículo 19 o 21 , inciso $2^{\circ}$, no establece que el Estado deba preferir y promover la acción de los particulares; no establece que -en caso que el Estado detecte adecuación por parte de los privados en el desarrollo de una determinada actividad de interés y relevancia social o pública- deba abstenerse de desarrollar una actividad similar y, lo más trascendente, no establece en cuál hipótesis el Estado o sus organismos podrán intervenir en un mercado cuyos actores privados demuestren insuficiencia, incapacidad o inadecuación.

Cuanto hemos señalado hasta el momento, creemos, demuestra que el artículo 19 No 21 no puede ser interpretado como una manifestación del principio de subsidiariedad. Creemos que esta norma tampoco encuentra su inspiración en él.

Se trata, en cambio, de una norma que entrega a una decisión simplemente política con la iniciativa de crear nuevas actividades empresariales en que el Estado sea parte o propietario. Y la decisión política -siempre

${ }^{72}$ GO Bayern, $\$$ 87: (1) Die Gemeinde darf ein Unternehmen im Sinn von Articulo 86 nur errichten, übernehmen oder wesentlich erweitern, wenn: (4) bei einem Tätigwerden außerhalb der kommunalen Daseinsvorsorge der Zweck nicht ebenso gut und wirtschaftlich durch einen anderen erfüllt wird oder erfüllt werden kann. (El autor agradece la indicación de esta norma al prof. Antonio D’Atena de la Università di Roma "Tor Vergata”). 
que alcance en el Parlamento el quórum calificado que la norma exigepuede disponer la creación de este tipo de empresas aun prescindiendo de toda verificación acerca de la presencia de los requisitos que -según el principio de subsidiariedad- las harían 'procedentes'.

La norma, asimismo, priva de herramientas de calificación a la justicia constitucional que podría ser llamada al control de constitucionalidad de una ley que autorice al Estado a desarrollar actividades económicas. Esta jurisdicción se encontraría limitada a verificar el cumplimiento de los requisitos -meramente formales - establecidos en la disposición del No 21 del artículo 19 C.Pol.

Por otro lado, debido a la interpretación restrictiva que se ha dado a la norma que nos ocupa (que pretende encontrar su fundamento en la subsidiariedad del Estado, que como hemos dicho, no se logra individualizar en esta norma) se corre el riesgo de impedir la actuación del Estado en aquellas actividades de naturaleza empresarial que sí son necesarias y relevantes para la sociedad y donde los particulares han demostrado su inadecuación para desarrollarla en modo mejor y económicamente más eficiente.

Una interpretación sistemática y conforme al principio de subsidiariedad del artículo 19 No 21 impone alentar y promover la actuación del Estado una vez que se verifique la incapacidad de los particulares y de las comunidades intermedias. Esa interpretación es difícil de fundar en el texto expreso de la norma puesto que, como se ha visto, ella permitiría con mayor facilidad extrapolar un principio de no intervención estatal lo cual se encuentra en abierto contraste con el núcleo del principio de subsidiariedad que hemos individualizado en precedencia.

El Estado de Derecho y el principio democrático, por el contrario, creemos que demanden una lectura de la norma que permita una mayor flexibilidad a favor del Estado que -en su calidad de promotor del bien común ex artículo 1 C.Pol.- debe estar atento a detectar aquellas falencias de la iniciativa privada que puedan poner en riesgo la obtención de esa finalidad fundamental que le ha sido asignada por la Carta Fundamental ${ }^{73}$.

\footnotetext{
${ }^{73}$ Lectura que, por otro lado, no es ajena a la más atenta doctrina italiana. En efecto, se señala, por un lado, que el principio de subsidiariedad, además de prestarse a una lectura "en negativo", en el sentido de limitar la injerencia de los poderes públicos en la esfera inviolable del individuo puede, por otro lado y en atención a la primacía del individuo respecto a las instituciones públicas, ayudar a afirmar la obligación de éstas de actuar activamente con el objeto de garantizar el libre desarrollo de la personalidad humana (así, CAMERLEngo, Quirino, Articolo 118, cit. (n. 59), p. 2.351: el principio de subsidiaridad "oltre a prestarsi ad una lettura 'in negativo' (nel senso di precludere ingerenze nella sfera inviolabile singolo), la primazia
} 


\section{CONCLUSIONES}

Creemos que este largo excursius nos permite avanzar las siguientes conclusiones.

En primer lugar, que el principio de subsidiariedad es tributario de una larguísima evolución histórica que parte ya en la Antigua Grecia pero que se solidifica recién en el siglo XX con la encíclica Quadragesimo anno, la cual pretende rescatar el valor de la iniciativa individual y, sobre todo de los cuerpos intermedios de la sociedad, de frente a un Estado excesivamente activo en la vida social. Sin embargo, el origen de este principio permite reconocer, también, un generoso aporte de las doctrinas económicas liberales, neo-liberales y sociales liberales que pretenden una reordenación de la posición del Estado en la economía.

En segundo término, esta riqueza de orígenes se manifiesta claramente en la polivalencia que los ordenamientos jurídicos modernos (y pensamos en particular en el ordenamiento de la Unión Europea y el italiano) han sabido reconocer y aplicar a este principio. No se trata, pues, solamente de limitar a ultranza la actuación del Estado sino que de modelarla en su complejidad y formas. La finalidad de esta actuación del Estado, y no podría ser de otro modo, es la consecución del bien común lo cual pasa, necesariamente, por la atención pública hacia las cuestiones que los individuos y la iniciativa de éstos y sus asociaciones no son capaces de satisfacer $y$ hacer frente.

Finalmente, creemos, nuestro país no ha recogido esta polivalencia y polifuncionalidad del principio. Por el contrario, nos hemos limitado a creer que nuestro ordenamiento constitucional consagra el principio y lo hemos leído principalmente -y, diríamos, casi exclusivamente- en su valencia negativa es decir, como principio de limitación de la actuación pública y no como principio modelador de la misma, olvidando, en lo fundamental, que la subsidiariedad debe comportar, también, un incentivo a la presencia del Estado en aquellas cuestiones que, siendo de relevancia pública, parecen desatendidas o insuficientemente satisfechas por la iniciativa de los individuos y los grupos intermedios.

Este principio, si es interpretado correctamente, se puede transformar en

dell'individuo rispetto alle pubbliche istituzioni può anche sorreggere l'obbligo per le stesse di adoperarsi attivamente affinché sia effettivamente garantito il libero svolgimento della personalità umana"), "además de prestarse a una lectura 'en negativo' (en el sentido de impedir injerencias en la esfera inviolable del individuo), la primacía del individuo respecto a las instituciones públicas puede también fundamentar la obligación para éstas de actuar activamente con el objeto que sea efectivamente garantizado el libre desarrollo de la personalidad humana”. 
una herramienta fundamental que permitiría al Estado alocar sus esfuerzos ahí donde son más necesarios, es decir, donde otros sujetos del complejo social no son capaces de actuar adecuadamente, cuidando de cumplir, de este modo, su finalidad última de existencia, es decir, el servicio al ciudadano, y la búsqueda del bien común del cuerpo social.

[Recibido el 7 de octubre y aceptado el 10 de novimenbre 2009]

\section{BIBLIOGRAFÍA}

AlBANESE, Alessandra, Il principio di sussidiarietà orizzontale: autonomia sociale e compiti pubblici, en Diritto Pubblico (2002).

ANTONINI, Luca, Il principio di sussidiarietà orizzontale: da welfare state a welfare society, en Rivista di Diritto Finanziario e Scienza delle Finanze (2000).

ARENA, Gregorio, Il principio di sussidiarietà orizzontale nell'artículo 118 u.c. della Costituzione, en Studi in onore di Giorgio Berti (Napoli, Jovene, 2005), I.

Aróstica Maldonado, Iván, Crónica sobre la expansión del estado empresario y el retraimiento de la iniciativa privada, en Ius Publicum 2 (1999).

Astorga Sepúlveda, Cristóbal, Las raices escolásticas del principio de subsidiariedad, en Revista Derecho y Humanidades 12 (2006).

Bauer, Carl J., Derecho y economía en la Constitución de 1980, en Revista Perspectivas 1 (1998).

Bertelsen Repetto, Raúl, El estado empresario en la Constitución de 1980, en Revista Chilena de Derecho 14 (1987).

BERTOLINI, CECILIA, La sussidiarietà amministrativa, ovvero la progressiva affermazione di un principio, en Diritto Amministrativo (2007).

Bulnes Aldunate, Luz, Visión académica de la Constitución económica de 1980, en Revista de Derecho Público 62 (2000).

Camerlengo, Quirino, Articolo 118, en Bifulco, Raffaele; Celotto, Alfonso; OlivetTI, Marco (eds.), Commentario alla Costituzione (Milano, Giuffrè, 2006), III.

CASSESE, Sabino, L'aquila e le mosche. Principio di sussidiarietà e diritti amministrativi nell'area europea, en Il Foro Italiano (1995).

Covarrubias Cuevas, Ignacio, El principio de subsidiariedad, en Navarro Beltrán, Enrique (editor), Veinte años de la Constitución Chilena: 1981-2001 (Santiago, Editorial Jurídica ConoSur, 2001).

D'ANDrea, Antonio, La prospettiva della Costituzione italiana ed il principio di sussidiarietà, en Jus (2000).

D'Atena, Antonio, Costituzione e principio di sussidiarietà, en Quaderni Costituzionali (2001).

D'Atena, Antonio, Dimensioni e problemi della sussidiarietà, en De Martin, Gian Candido (editor), Sussidiarietà e democrazia. Esperienze a confronto e prospettive (Padova, Cedam, 2008).

D'Atena, Antonio, Il principio di sussidiarietà, en el MISMO, Lezioni di diritto costituzionale (Torino, Giappichelli, 2001).

D'Atena, Antonio, La sussidiarietà tra valori e regole, en Diritto e Giurisprudenza Agraria e dell'Ambiente (2004). 
Deaglio, Mario, Sussidiarietà, istituzioni economiche, imprese, en Curzio Quadrio, Alberto; ForTis Marco (editores), Valorizzare un'economia forte. L'Italia e il ruolo della sussidiarietà (Bologna, Il Mulino, 2007).

Di Nella, Luca, La Scuola di Friburgo o dell'ordoliberalismo, en Natalino IRTI (ed.) Diritto ed Economia. Problemi e orientamenti teorici (Padova, Cedam, 1999).

Duret, Paolo, La sussidiarietà orizzontale: le radici e le suggestioni di un concetto, en Jus (2000).

Fermandois Vöhringer, Arturo, Derecho constitucional económico (2a Santiago, Ediciones Universidad Católica de Chile, 2006), I.

Ferroni, Maria Victoria, Principio di sussidiarietà e negoziazione urbanistica (Torino, Giappichelli, 2008).

Fontaine Talavera, Arturo, El miedo y otros escritos. El pensamiento de Jaime Guzmán Errázuriz, en Estudios Públicos 42 (1991).

Frosini, Tommaso Edoardo, Sussidiarietà (Principio di) (Dir. cost.), en Enciclopedia Giuridica (Milano, Giuffrè, 2008), II.

Gerber, David J., Constitutionalizing the Economy: German Neoliberalism, Competition Law and the "New" Europe, en The American Journal of Comparative Law vol. 42 (1994).

GÖTZ, Volkmar; HeCKER, Michael, Il principio di sussidiarietà nel diritto costituzionale tedesco con particolare riferimento alla sua dimensione federale, en Angelo RINELLA Leopoldo CoEN - Roberto SCARCiglia - Michele Mistò (editores) Sussidiarietà e ordinamenti costituzionali. Esperienze a confronto (Padova, Cedam, 1999).

Huidobro Salas, Ramón, El derecho a desarrollar cualquier actividad económica en las actas de la Comisión de Estudios de la Nueva Constitución, en Revista de Derecho Público 43-44 (1988).

Massa PInTo, Ilenia, Il principio di sussidiarietà. Profili storici e costituzionali (Napoli, Jovene, 2003).

Millon-Delsol, Chantal, Il principio di sussidiarietà (Trad. it. di Massimo Tringali, Milano, Giuffrè, 2003)

Moscarini, Anna, Sussidiarietà e libertà economiche, en Diritto e Società (1999).

PAPa Pío XI, Carta encíclica Quadragesimo anno (1931) accedido en www.vatican. va.

Picozza, Eugenio, Introduzione al diritto amministrativo (Padova, Cedam, 2006).

Ruiz-Tagle Vial, Pablo, Principios constitucionales del Estado empresario, en Revista de Derecho Público 62 (2000).

SAN Francisco Reyes, Alejandro, Jaime Guzmán y el principio de subsidiariedad educacional en la Constitución de 1980, en Revista Chilena de Derecho 19 (1992).

SCHÜRmann, Miguel, Orden público económico y principio de subsidiariedad, argumentos para una critica, en Revista Derecho y Humanidades 12 (2006).

Soto Kloss, Eduardo, La actividad económica en la Constitución Politica de la República de Chile (La primacia de la persona humana), en Ius Publicum 2 (1999).

TAPIA VALDÉs, Jorge, Descentralización y subsidiariedad en la época de la globalización, en Revista del Centro de Estudios Constitucionales de Chile 1 (2003).

Vallejo Garreton, Rodrigo - Pardow Lorenzo, Diego, Derribando mitos sobre el estado empresario, en Revista Chilena de Derecho 35 (2008).

VARELA DEL SOLAR, Jorge, Subsidiariedad, orden público económico y seguridad nacional en la Constitución de 1980, en Revista Chilena de Derecho 16 (1989). 